\title{
Article \\ Climatic Analysis of Wind Patterns to Enhance Sailors' Performance during Races
}

\author{
Pietro Masino $^{1, *}$, Roberto Bellasio ${ }^{2}{ }^{\oplus}$, Roberto Bianconi ${ }^{2}$, Angelo Besana ${ }^{1}$ and Alessandro Pezzoli ${ }^{1}$ \\ 1 Interuniversity Department of Regional and Urban Studies and Planning (DIST), Politecnico di Torino \& \\ University of Turin, 10125 Torino, Italy; angelo.besana@unito.it (A.B.); alessandro.pezzoli@polito.it (A.P.) \\ 2 Enviroware srl., Via Dante 142, 20863 Concorezzo (MB), Italy; rbellasio@enviroware.com (R.B.); \\ rbianconi@enviroware.com (R.B.) \\ * Correspondence: pietro.masino@edu.unito.it
}

Citation: Masino, P.; Bellasio, R.; Bianconi, R.; Besana, A.; Pezzoli, A. Climatic Analysis of Wind Patterns to Enhance Sailors' Performance during Races. Climate 2021, 9, 80. https:// doi.org/10.3390/cli9050080

Academic Editor: Salvatore Magazù

Received: 20 March 2021

Accepted: 8 May 2021

Published: 13 May 2021

Publisher's Note: MDPI stays neutral with regard to jurisdictional claims in published maps and institutional affiliations.

Copyright: (c) 2021 by the authors. Licensee MDPI, Basel, Switzerland. This article is an open access article distributed under the terms and conditions of the Creative Commons Attribution (CC BY) license (https:// creativecommons.org/licenses/by/ $4.0 /)$.

\begin{abstract}
The impact of environmental and meteorological conditions when dealing with sport performance has been demonstrated by several studies carried out in recent years. Among the meteorological variables with the greatest effect are temperature, humidity, precipitation, and wind direction and speed. This research focused on analyzing and forecasting the wind patterns occurring in Enoshima Bay (Japan). In particular, the objective of this study was to provide support and guidance to sailors in the preparation of the race strategy, thanks to an in-depth knowledge of these meteorological variables. To do this, an innovative method was used. First, through the combined use of Weather Research and Forecasting (WRF) and CALMET models, a simulation was performed, in order to reconstruct an offshore database of a recent 10-year period (2009-2018) over the race area, inside the bay. Subsequently, the verification of hind-cast was performed: the wind data measured at sea were compared with the data extracted from the CALMET database to verify the validity of the model. The verification was performed through three statistical indexes: BIAS, MAE, and PCC. The analysis showed mixed results, depending on the examined pattern, but made it possible to identify the days that best simulated the reality. Then, the wind data from the selected days were summarized and collected in plots, tables, and maps to design a decision support service (DSS), in order to provide athletes with the necessary information in a simple and effective way. In conclusion, we state that the application of this method extends beyond the sports field. Indeed, the study of wind patterns may be necessary in the design of actions to contrast and adapt to climate change, particularly in coastal areas.
\end{abstract}

Keywords: wind pattern; numerical weather prediction; sailing race strategy; meteorological variables; statistical analysis; climatological analysis; decision support service

\section{Introduction}

A profound knowledge of the meteorological variables, acquired through a reliable forecast system, is fundamental in a wide variety of research fields [1-7].

Regarding sport events, the importance of meteorological information is supported by athletes, sports managers, and meteorologists. The results of multiple recent studies have confirmed that weather conditions can strongly affect athletes' performance. There are many case studies in several sports like marathons (El Helou et al. [8]), cycling (Pezzoli et al. [9]; Peiffer et al. [10]), and soccer (Buchheit at al. [11]). These studies are significant both for the meteorological research side and for the sport performance side, but they can also be relevant for the physiological and medical area. For example, on the occasion of the Olympic Games in Rio de Janeiro, Pezzoli et al. [12] evaluated the thermal comfort of cycling athletes, in order to maximize their performance and to preserve their physical integrity in hard weather conditions. In another study, Golding et al. [13] discussed and demonstrated, with an application during the 2012 London Olympic and Paralympic 
Games, how the provision and performance of advanced numerical modeling capabilities are important in the management of major sporting events.

Focusing on the specific research field and the main objective of this study, the literature is even more extended. For example, in preparation for the 2008 Olympic sailing event, $\mathrm{Li}$ [14] investigated the proprieties of the Qingdao coastal wind fields. The author analyzed the wind data retrieved from the SeaWinds scatterometer on board the QuikSCAT satellite for historical Augusts from 1999 to 2007. He also utilized the Advanced Synthetic Aperture Radar (ASAR) to gain high resolution images of the coastal wind field. Finally, ASAR and QuikSCAT data were compared to the in situ buoy measurements. The results of the comparison demonstrated that the wind data extracted from ASAR give a better picture of the reality, since QuikSCAT could not provide the wind data close to the coast.

For the 2016 Olympic sailing event held in Rio de Janeiro, Giannaros et al. [15] used AEOLUS-RIO2016, an ultrahigh resolution wind forecasting system. The forecasting system was built around the Weather Research and Forecasting (WRF) model, ported to a highperformance computing infrastructure that ensured the reliability and timeliness of the provided service [15]. Due to the complexity of the terrain, two updated high-resolution datasets replaced the standard ones of the model: the Shuttle Radar Topography Mission (SRTM) for topography and the GlobeCover 2009 for land use. The wind data extracted from AEOLUS-RIO2016 were compared with the data collected at four different locations inside the race area, in order to verify the reliability of the model. The results showed that the employment of the two updated datasets improved AEOLUS-RIO2016 performance in terms of wind forecasting.

Spark et al. [16] faced a similar problem in the wind forecasting for the sailing events at the Sydney 2000 Olympics. The topography of the Sydney area is very intricate, so it had been necessary to develop different statistical tools to supplement the numerical weather prediction (NWP) output. Two high resolution NWP models were implemented: LAPS 05 and a model provided by the University of New South Wales Center for Environmental Modeling and Prediction (CEMAP), which was available at $5-\mathrm{km}$ and $1-\mathrm{km}$ resolutions. In addition, to support the forecasting process, five statistical models were used, trying to account for small-scale wind variations due to terrain and local sea-harbor breeze circulations. Then, the comparison between the predicted and observed data allowed for the evaluation of the prediction skill of each model. The statistical indices employed for the comparison were the index of agreement, the root-mean-square error, the wind bearing error, the magnitude of vector error, and Brier Skill Score.

The LAPS 05 model presented the most performing results, but the authors claimed that the ability of mesoscale NWP models to represent topography and local circulations should be further enhanced.

Recently, Messager et al. [17] described a limited area model explicitly resolving the convection used to generate weather forecasts for the Emirates Team New Zealand challenger in the 35th Americas' Cup, which occurred during spring 2017 in Bermuda.

It must be remembered that the race strategy does not depend only on the wind fields, particularly during the competition it can be affected by many other factors, like the racing rules or the behavior of the opponent. For this reason, Tagliaferri et al. [18] developed a method that combined all of these factors through dynamic programming to compute an optimal route. The wind variability was modeled with the use of neural networks, the willingness of the sailor to risk was modeled using coherent-risk measures, and the experimental results were utilized to quantify the loss of speed due to the presence of a nearby opponent. The results showed that this method can really increase the probability of winning, but the fact that the wind was assumed constant across the whole race area highlights that it can be further improved.

Compared to the other studies above-mentioned, this one aimed to study the wind patterns (WP) occurring in Enoshima Bay, Japan (see Figure 1), during what would have been the 2020 Olympic period (24 July-9 August 2021, delayed for the COVID pandemic). 


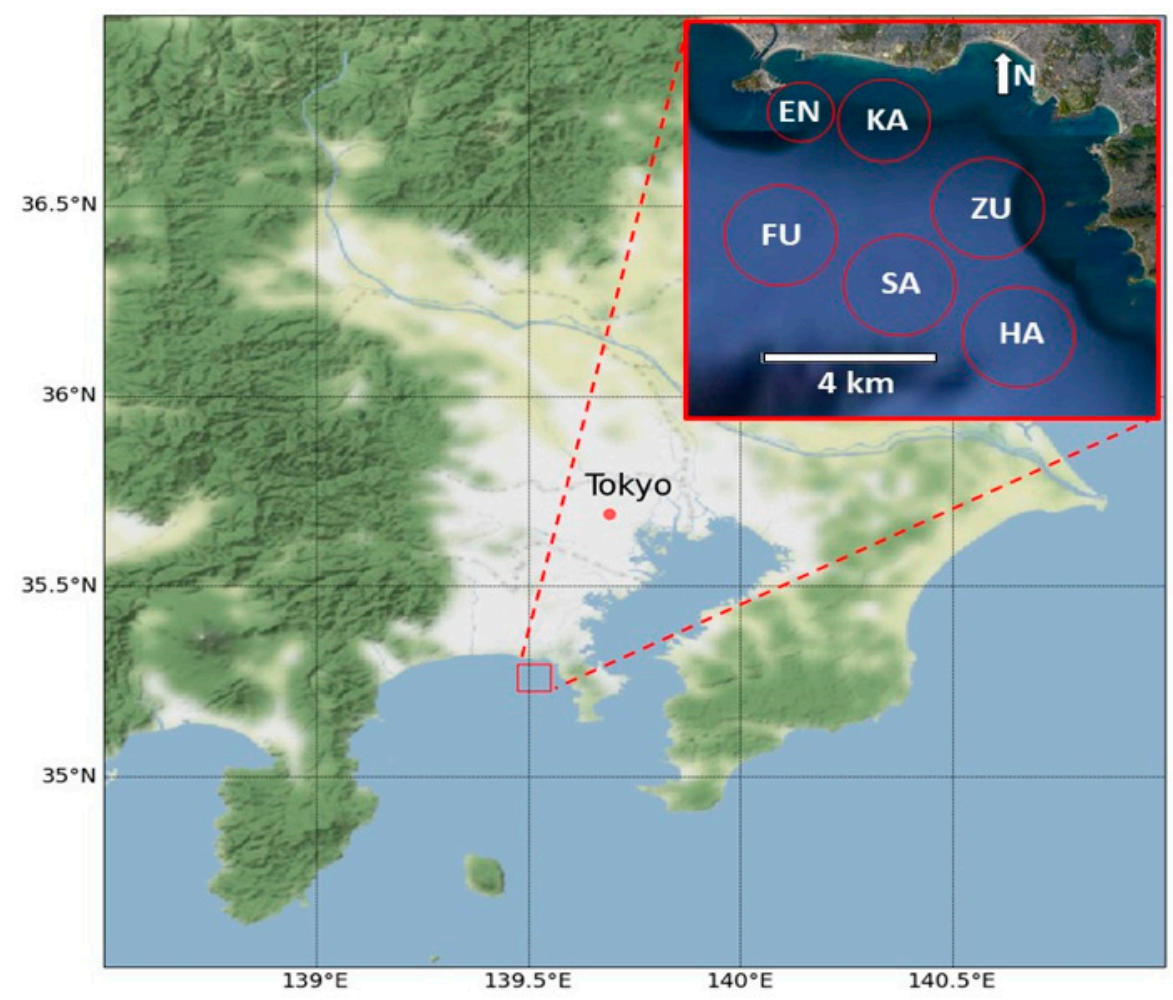

Figure 1. Location of Enoshima Sailing Venue (red rectangle) with respect to Tokyo. The racing areas are named Enoshima (EN), Kamakura (KA), Zushi (ZU), Fujisawa (FU), Sagami (SA), and Hayama (HA).

In fact, the previously mentioned studies focused on the measurements carried out with remote sensing or on the meso-scale models used for forecast purposes. Instead, the present research aimed to focus on the use of a database, built with a high-resolution model (CALMET), to design a forecast tool called "call book". While the methodology of the climatic downscaling was applied in other research areas such as aviation meteorology, wind energy applications, etc. [1-7], this methodology was applied for the first time in the sports field and represents an innovative methodology for sailing sports. In fact, in the cited sport (sailing), it is usual to analyze the race area using only the data measured by the in situ instruments (meteorological buoy, boats instrumented with anemometers, etc.) or by remote sensing [14] that required long measuring times to have a reliable dataset. Unfortunately, during an Olympic campaign, the time for the measurements is no longer than three years, not enough to have a reliable dataset for climatic analysis. For this reason, as indicated above, it was interesting to test the methodology of the climatic downscaling applied in other research areas (transport, energy, etc.) to the sport's application. In this way, it is possible to build a long database for an assigned period that, if well calibrated with the in situ measurements, represents, in fact, "virtual measurements" for each simulated point of the high-resolution model. Additionally, in sailing sport, it is interesting to know the micrometeorological factors (i.e., oscillations of the wind, etc.) other than a simple average of wind speed and direction. To derive this crucial information, the only way is to have very dense measurements in situ for a long time period that, as we have said before, is impossible for time constraints. Instead, using the presented methodology, it is possible to have a dense meteorological information for a long period that can be used to build the "call book" of the race area with an appropriate methodology, as presented in Section 2.

In fact, gaining knowledge on the weather and atmospheric conditions in the race areas, especially regarding wind patterns, is fundamental for sailors to prepare the best race strategy and to design the materials for the boats and garments for the athletes. The wind analysis allows for defining the strategic types of the regatta field as those where wind varies in the different zones both in direction and speed; wind varies in the different zones 
for direction and not for intensity; and wind varies in different zones for intensity and not for direction [19]. To this end, a new methodology was used, combining the analysis of climatological wind data, meteorological data measured at sea during the training activities, and the results of the CALMET model simulation. First, an offshore database of the recent 10-year period (2009-2018) was built for the period of the Tokyo Olympic Games (24 July-9 August), thanks to a combined use of the WRF and CALMET models. Later, consequently, the meteorological variables were extracted from the database and utilizing ternary plots, it was possible to identify the wind patterns over the race areas. This innovative methodology to analyze the correlation between wind speed, wind direction, and a third meteorological variable (air pressure, temperature, and cloud coverage) was very important to identify the prevailing weather patterns and the related wind patterns.

Once the wind patterns were established, an in-depth climatological analysis was carried out to select the days that best fit within the patterns from the CALMET database. The data of wind speed and direction were taken from the NOAA online meteorological archive, recorded every day, at three-hour intervals (precisely from 00.00 GMT to 9.00 GMT, or 9.00-18.00 LT) and a $925 \mathrm{hPa}$ of height to identify the gradient wind that characterized the related wind pattern. Through this analysis, 32 days were selected and extracted from the CALMET dataset and employed for the verification of the validity and sensitivity of the model. The data from the simulation were compared with the data observed on the field. The data were collected through weather stations located on seven boats in motion, continuously recorded. The comparison was performed through three statistical indices: the BIAS, the mean absolute error (MAE), and the Pearson correlation coefficient (PCC). With this analysis of sensitivity, the results of the model were compared with the measurements made in situ during the summer of 2019. The sensitivity analysis (see Sections 2.5 and 3.2). With this re-analysis, an improvement of the call book was made, and, after the 2018 edition, a new and improved edition of the call book was issued in February 2020. The final step was the design of the decision support service (DSS): the wind data of the days that best performed in the statistical analysis were used to build the wind map-in the QGIS software-and the charts and graphs that compose the DSS. The DSS is a very simple tool that summarizes the most important information (i.e., oscillations of the wind, maximum left and maximum right in the direction of the wind, differences in the wind speed in the race area, etc.) for a sailor and a coach to understand the wind situations in a race area and to make critical decisions during the race.

This method has two great elements of innovation in the sport research field: the historical wind data that have been reproduced with the CALMET model and used as climatic data, and the capability of the DSS to learn from its previous versions and be easily fixed and updated. Thanks to this innovative methodology, this paper aimed to achieve an extensive knowledge of the environmental and meteorological conditions to help athletes perform at their best during the assigned competition. For this reason, the climatic analysis focused only on the period of the Olympic Games (24 July-9 August) for the recent 10-years (2009-2018) to obtain a significant database because it will be used to build the DSS valid during the Olympic period. In this way, the DSS is the tool helping the athletes and the coaches in the strategical decisions regarding the Olympic races.

The structure of the present research is as follows. Section 2 describes the materials and methods utilized, like CALMET, WindRose, QGIS, the statistical indices, and the DSS. Section 3 reports the main results of the wind and statistical analysis and the design of the DSS. Sections 4 and 5 present the final discussion and the key conclusions.

\section{Materials and Methods}

The racing area planned for the Sailing Sport of the Tokyo 2020 Olympic Games had to be Enoshima Bay (https:/ / tokyo2020.org/en/venues/enoshima-yacht-harbour, accessed on 10 May 2021).

Enoshima is placed about $50 \mathrm{~km} \mathrm{SW}$ from the Tokyo urban area and outside the Bay of Tokyo. The race areas are called, respectively from west to east and from "in-shore" to 
"off-shore", Enoshima (EN), Kamakura (KA), Zushi (ZU), Fujisawa (FU), Sagami (SA), and Hayama (HA), as shown in Figure 1.

The effect of the topography in the land and sea breeze circulation was studied by Kikuci et al. [20] as well as by Hinata et al. [21], who studied the relationship between the wind patterns and the Kuroshio sea surface current.

In the present research, a deep examination of the wind patterns in the Enoshima Bay was developed, and the results are described in Section 3.

\subsection{The WRF and CALMET Models}

The Weather Research and Forecasting (WRF) [22] model is a next-generation mesoscale numerical weather prediction system designed for both atmospheric research and operational forecasting needs. It has been developed cooperatively by NCEP (National Centers for Environmental Prediction), NCAR (National Center for Atmospheric Research), and the meteorological research community. Two main configurations exist: WRF NMM (Nonhydrostatic Mesoscale Model) and WRF ARW (Advanced Research WRF). The initial and lateral boundary conditions are provided to WRF by a larger-scale dataset derived from global models.

WRF is a complex model that requires scientific knowledge and high computational resources to be used. The classical steps to run WRF are as follows:

- Definition of the simulation domains and interpolation of various terrestrial datasets to the model grids. In addition to computing latitude and longitude for every grid point, a series of interpolations of geophysical variables to the model grids is carried out (e.g., soil categories, land use category, terrain height, etc.).

- Unpacking of meteorological data from GRIB format and packing them into an intermediate file format.

- Horizontal interpolation of the ungribbed meteorological data onto the coarse model domain.

- Vertical interpolation of the files generated in the previous phase, creation of boundary and initial condition files. Some consistency checks are also performed during this phase.

After all the previous points, the simulation of the WRF meteorological model can start. The simulations require powerful Linux servers and can be done by means of cloud computing.

CALMET [23] is a diagnostic meteorological model that reconstructs the 3D wind and temperature fields starting from meteorological measurements, orography, and land use data. CALMET also contains algorithms for calculating micro meteorological variables, which are typically needed by atmospheric dispersion models (mixing height, MoninObukhov length, friction velocity, convective velocity, and others).

The diagnostic wind field module of CALMET operates with two consecutive steps. During the first one, an initial guess wind field is adjusted for kinematic effects of terrain, slope flows, and terrain blocking effects. The second step consists of an objective analysis procedure to introduce observational data to produce a final wind field. During the second step, CALMET needs meteorological observations at the surface (wind speed, wind direction, temperature, cloud cover, ceiling height, surface pressure, relative humidity and precipitation rate) and at least twice daily, aloft (wind speed, wind direction, temperature, pressure, and height). During the first step (initial guess), CALMET can use the output of a prognostic meteorological model such as WRF. The output of prognostic models can be used in other two ways: as a replacement for the meteorological fields obtained at the end of the first step, or as pseudo observations in the objective analysis procedure. The prognostic wind fields have the advantage of better representing regional flows and certain aspects of sea breeze circulations and slope/valley circulations.

Recently, a modified version of CALMET including improved algorithms to estimate solar radiation and temperature over complex topography [24] has been used in mountain- 
ous and hilly terrain $[25,26]$. However, in this work, the original version of CALMET was used because the terrain is relatively flat.

\subsection{The Windrose PRO3 Software}

The Windrose PRO3 software [27] was used to analyze wind data, draw wind roses, and ternary plots. A wind rose is a chart that gives a view of how wind speed and wind direction are distributed in a specific location. The size of each chart's segment is determined by the wind speed class frequency (percentage values are shown by the circles) while the angle from North in the clockwise direction depends on the wind direction. In a ternary plot, in addition to wind speed and wind direction, a third variable is considered, for example, the atmospheric pressure. A time filter option allows for producing wind roses for specific time periods (months, days, and hours) and an interval option allows creating different range sizes for the considered variable.

\subsection{Geographic Information System}

A geographic information system (GIS) is an integrated set of software and data used to produce geographical information, analyze spatial relationships, and model spatial processes. A GIS can support decisions concerning the management of a specific territory, like urban planning, management of public transportation, demographics, and logistics. A GIS can also be useful in the field of environmental protection, agriculture and forestry, risk management, public health, and energy production [28-33].

For this study, we employed QGIS software, an open-source GIS designed to store, analyze, and manage spatial and geographic data. QGIS encompasses several different functions like vector and raster analysis, sampling, geoprocessing, thematic mapping as well as database management tools.

By uploading the data, extracted from the CALMET database, into QGIS, we built the "wind maps", a powerful tool that gives an immediate picture of the wind behavior and whether it follows the "rules" of the pattern assigned to that day.

\subsection{The WRF and CALMET Simulations}

WRF (version 3.9.1, ARW core) was initialized with the NCEP FNL (Final) Operational Global Analysis data (https:/ / rda.ucar.edu/datasets/ds083.2/, accessed on 10 May 2021), operationally prepared every six hours on a $1 \times 1$ degree grid. WRF was run at 45 vertical levels, up to $50 \mathrm{mb}$, and a 3-level domain nesting was used, with domain resolutions of $18 \mathrm{~km}, 6 \mathrm{~km}$, and $2 \mathrm{~km}$, respectively. The innermost WRF domain extends about $150 \times 140 \mathrm{~km}^{2}$ along both longitude and latitude (green rectangle in Figure 2 including Tokyo urban area).

The datasets and physical parameterizations used in WRF are summarized in Table 1. The WRF simulations were carried out for the period July 24 to August 9 of the ten-year interval 2009-2018 by means of cloud computing [34]. Instead of sensitivity analysis of the WRF model, it was decided, for time constraints in the project, to directly develop a reliability analysis of the CALMET outputs. Moreover, it is important to point out that an accurate analysis of the CALMET results is fundamental in this research because these outputs are the data used to build the DSS.

CALMET (version 6.5.0, level 150223) was employed on a domain of $32 \times 32 \mathrm{~km}^{2}$, with a grid resolution of $200 \mathrm{~m}$ (yellow square in Figure 2 focused on the Enoshima race area) to downscale the WRF predictions. It was observed that WRF could be used directly with a grid resolution of $200 \mathrm{~m}$, avoiding the use of CALMET. However, the computational and time resources needed with that option would be huge. Since the methodology must have practical applications, we adopted CALMET to downscale the WRF meteorological fields. 


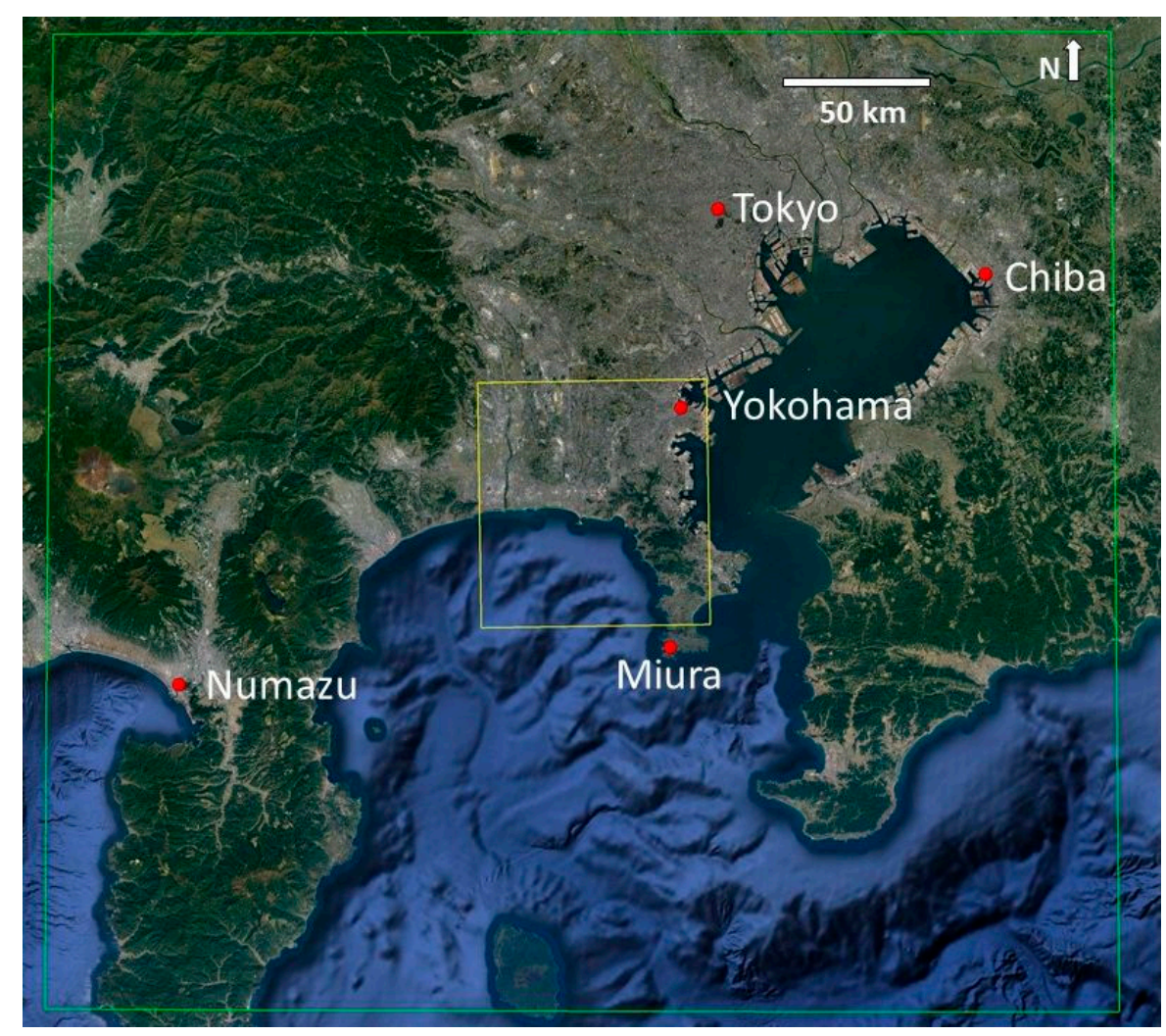

Figure 2. WRF inner domain (green rectangle) and CALMET domain (yellow square).

The UTM 54S coordinates of the lower left corner of the CALMET domain are (348000, 3893000). CALMET was fed by the 1-h time resolution output of WRF over its inner domain. In order to pair WRF and CALMET, the CALWRF processor was used. WRF data were used as the initial guess field by CALMET. For each one of the ten years considered in the simulations - over the time interval 24 July to 9 August - the meteorological variable output of CALMET was determined with a time resolution of $20 \mathrm{~min}$. To perform the statistical analysis, build the patterns and the wind maps, we wanted to have only one value per hour. Hence, for each sixty-minute interval, we selected the output of the first twenty as the representative value of the whole hour. This value was extracted as the most representative value for the hourly interval because it was the closest value to the hourly measurements.

The average terrain elevation over each $200 \times 200 \mathrm{~m}^{2}$ grid cell was determined starting from the Shuttle Radar Topography Mission (SRTM) data [35]. The terrain elevation over the CALMET domain is shown in Figure 3.

The high-resolution land use data were obtained from the Japan Aerospace Exploration Agency (JAXA) [36]. The prevailing land use over each $200 \times 200 \mathrm{~m}^{2}$ grid cell was determined by processing these data. The result is shown in Figure 4. 


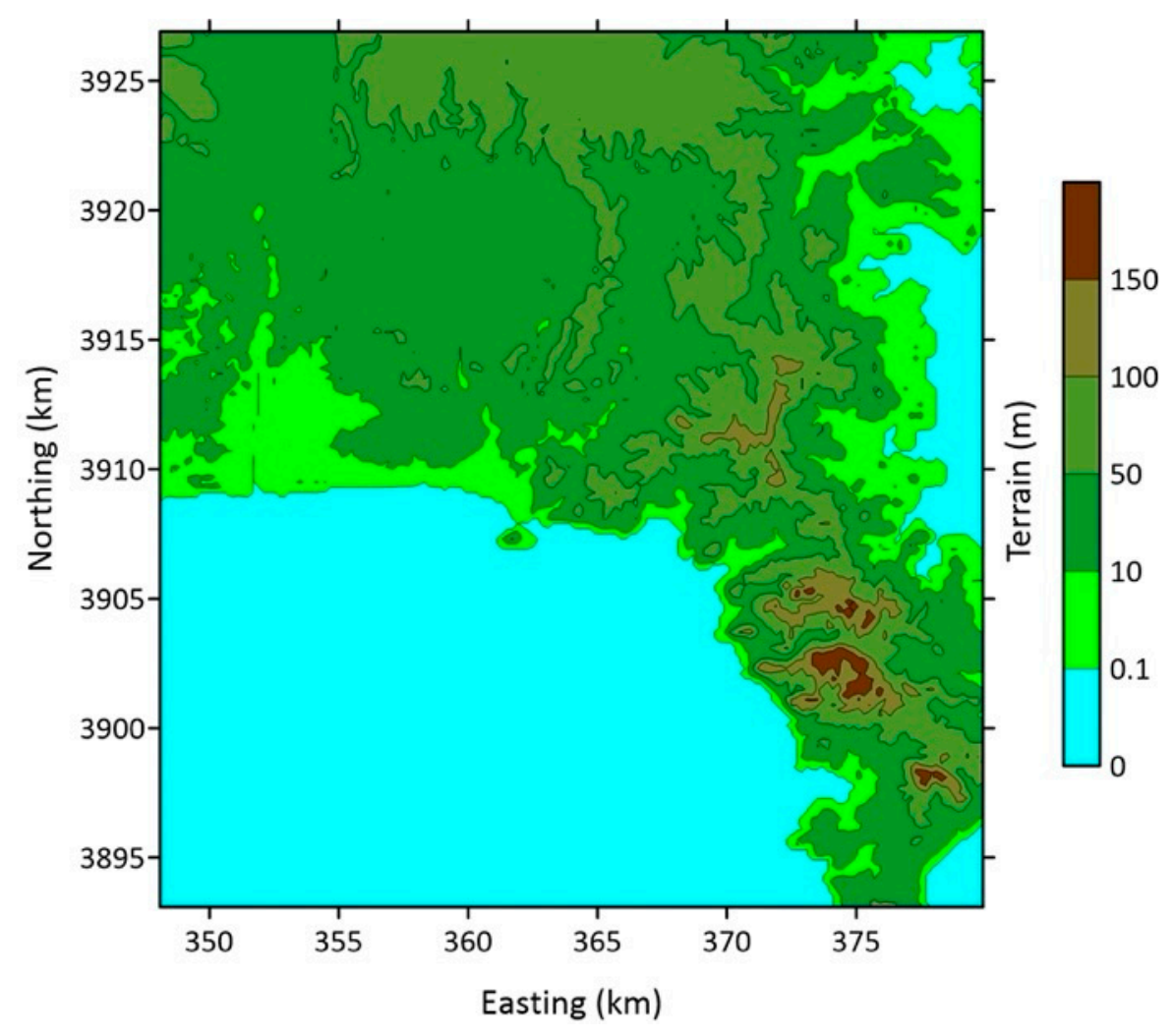

Figure 3. Terrain elevation over the CALMET domain.

Table 1. WRF model configuration.

\begin{tabular}{|c|c|}
\hline Physical Process & Scheme \\
\hline Initial and boundary & $\begin{array}{l}\text { NCEP FNL (Final) Operational Global Analysis data } \\
\text { (https: / / rda.ucar.edu/datasets/ds083.2/, last access: } 11 \text { May 2021) }\end{array}$ \\
\hline Terrain Elevation & $\begin{array}{l}\text { Global 30-arc second and USGS GMTED2010 (https:/ / www.usgs.gov / core-science- } \\
\text { systems / eros / coastal-changes-and-impacts/gmted2010, last access: } 10 \text { May 2021) }\end{array}$ \\
\hline Land Use & $\begin{array}{c}\text { Global 30-arc second and 21-category IGBP-Modified MODIS land use classification } \\
\text { with lakes (https:/ / ftp.emc.ncep.noaa.gov/mmb/gcp/ldas/noahlsm/, last access: } 10 \\
\text { May 2021) }\end{array}$ \\
\hline Vegetation Fraction & $\begin{array}{c}\text { Global 30-arc second monthly Greenness Vegetation Fraction based on } 10 \text { years MODIS } \\
\text { (FPAR) (https://modis.gsfc.nasa.gov/data/dataprod/mod15.php, last access: } 10 \\
\text { May 2021) }\end{array}$ \\
\hline Leaf Area Index & $\begin{array}{l}\text { Global 10-arc minute monthly Leaf Area Index (LAI) data based on } 10 \text { years MODIS } \\
\text { (https:/ / modis.gsfc.nasa.gov/data/dataprod/mod15.php, last access: } 10 \text { May 2021) }\end{array}$ \\
\hline Soil Type & $\begin{array}{l}\text { Global 10-arc minute 16-category soil type dataset } \\
\text { (https:/ /agupubs.onlinelibrary.wiley.com/doi/full/10.1002/2015JD024558, last } \\
\text { access: } 10 \text { May 2021) }\end{array}$ \\
\hline Longwave radiation & Rapid Radiation Transfer Model (RRTM) [37] \\
\hline Shortwave radiation & Dudhia [38] \\
\hline Planetary Boundary Layer (PBL) & Yonsei University (YSU) [39] \\
\hline Cumulus & Kain-Fritsch [40] \\
\hline Microphysics & Lin et al., [41] \\
\hline Atmospheric processes near the surface & $\begin{array}{l}\text { NOAH Land Surface Model (with datasets USGS, USGS+lakes, MODIS, and } \\
\text { MODIS+lakes) } \\
\text { (https:/ / ral.ucar.edu/solutions / products/wrf-noah-noah-mp-modeling-system, last } \\
\text { access: } 10 \text { May 2021) }\end{array}$ \\
\hline
\end{tabular}




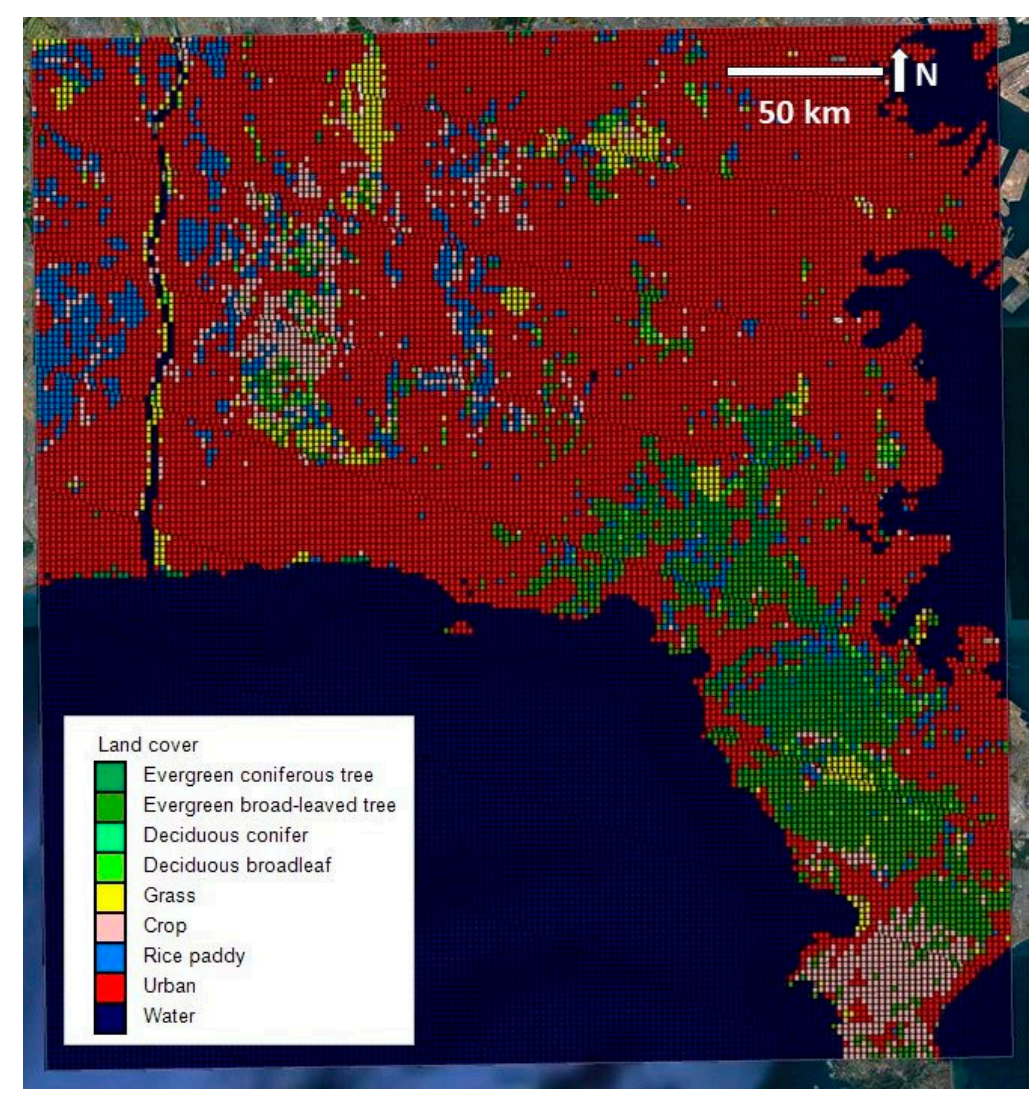

Figure 4. Prevailing land use over each CALMET grid cell.

\subsection{Statistical Indices}

The evaluation of the forecasting model is a crucial step in this kind of research, and it can be performed through different statistical methods. In the context of sailing events, the most utilized statistical indices are the bias, the mean absolute error (MAE), the root mean square error (RMSE), the wind bearing error (WBE), the index of agreement (IOA), and the Pearson correlation coefficient (PCC) $[15,16,19,42,43]$. These statistical techniques are employed other research fields like wind power forecasting [7], airport operations design [4,5], and pollutant concentration prediction [44-47].

In this study, for the comparison, we used the data observed in the field during the summer of 2019 and collected through weather stations placed on seven boats located in the race area.

Then, to verify the accuracy of the model, the following indices were calculated.

\subsubsection{BIAS}

The BIAS gives information about over-prediction or under-prediction of the model data. It is calculated as follows

$$
\mathrm{BIAS}=\frac{1}{n} \sum_{k=1}^{n}\left(p_{k}-o_{k}\right)
$$

where $n$ is the number of observations; $p_{k}$ is the $k$-th predicted value; and $o_{k}$ is the corresponding $k$-th observed value [19]. Positive BIAS values indicate over-predictions while negative values indicate under-predictions. This statistical index alone is not sufficient because, for example, a value close to zero may indicate an almost perfect matching between prediction and observation or the result of a perfect balance between positive and negative values. 


\subsubsection{Mean Absolute Error}

The MAE gives information about the absolute difference between prediction and observation. The MAE is defined as

$$
\text { MAE }=\frac{1}{n} \sum_{k=1}^{n}\left|p_{k}-o_{k}\right|
$$

where $n$ is the number of observations; $p_{k}$ is the $k$-th predicted value; and $o_{k}$ is the corresponding $k$-th observed value. MAE is useful when compared to the BIAS: a value close to zero may confirm the perfect matching, while values far from zero can reveal a false match of the BIAS results.

\subsubsection{Pearson Correlation Coefficient}

The PCC provides a measure of the linear correlation between variations in time of observed and predicted values. The PCC formula is

$$
\mathrm{PCC}=\frac{\sum_{k=1}^{n}\left(p_{k}-p_{a v g}\right)\left(o_{k}-o_{a v g}\right)}{\sqrt{\sum_{k=1}^{n}\left(p_{k}-p_{a v g}\right)^{2}} \sqrt{\sum_{k=1}^{n}\left(o_{k}-o_{a v g}\right)^{2}}}
$$

where $p_{\text {avg }}$ and $o_{\text {avg }}$ are respectively the averages of predictions and observations over a specific time period.

The PCC gives values within -1 (complete counter correlation) and +1 (complete correlation) with simple interpretation: a positive value indicates a positive agreement, while a negative value indicates that the observations and predictions are varying with opposite sign over time.

\subsection{The Decision Support Service}

The main component of the DSS is the "call book", a simple and effective guide designed to help athletes and coaches in the preparation of race strategies. The guide summarizes the meteorological data of the six race fields in tables, plots, and cartographic representations with brief descriptions to be easily understood and quickly consulted. These kind of communication tools have been developed by Houghton et al. [48].

The guide includes the wind-roses produced on the competition fields by means of Windrose PRO3 software and reports all the wind patterns identified during the analysis. For each race field, a typical day between 24 July and 9 August, was reconstructed with the hourly data from 09:00LT to 18:00LT-a typical time interval in which competitions take place - and represented by the wind maps employing QGIS software.

The DSS is a great and innovative system that can confer a valuable advantage to the sailors who use it for two main reasons. First, the use of a limited scale meteorological model in hindcasting compensates for the lack of continuous measurements at sea, providing a distributed analysis of wind fields [19]. Second, this system "learns" from errors, in the sense that it can be easily corrected and updated as new measurements are made.

\section{Results}

\subsection{The Wind Patterns}

The initial step to create the wind patterns was the identification of the wind behavior inside the bay for the selected period. The CALMET database was processed by Windrose $\mathrm{PRO} 3$ to provide the wind roses, with hourly frequency, of the six race fields: Enoshima (EN), Kamakura (KA), Fujisawa (FU), Sagami (SA), Zushi (ZU), and Hayama (HA). The six race areas showed the same behavior with prevailing directions from S and SSW and a constant increase in speed during the day:

- 09:00LT: SW and SSW are the prevailing directions with slightly influences of E light breeze and NE moderate breeze. The average speed is around $5 \mathrm{kts}$ with $3.7 \%$ of calms (speed under 1 knot). 
- 10:00LT: prevailing direction changes to S-SSW with less interference from $\mathrm{N}$ and $\mathrm{E}$ wind; the speed rises by $1-1.5 \mathrm{kts}$ and the calms decrease to $1.7 \%$.

- 11:00LT-12:00LT: S is the main direction with SSW gusts up to $20 \mathrm{kts}$; calms are negligible and wind speed average rises from 8.5 to $9.5 \mathrm{kts}$.

- 13:00LT-14:00LT: usual prevailing directions while average speed intensifies up to 11 kts; strong breeze from SSW.

- 15:00LT-16:00LT: period of the day with maximum wind speed; highest values still have a SSW direction.

- 17:00LT-18:00LT: S-SSW is still the main direction with a small decline in speed.

Then, to identify the patterns, we built the ternary plots of Enoshima (northernmost field) and Hayama (southernmost field) by comparing wind speed, wind direction, and atmospheric pressure. The atmospheric pressure, measured between 09:00LT and 18:00LT, is represented by circles in different color scales placed at radial distance given by the correspondent wind speed and at an angular coordinate by the correspondent wind direction. A third variable, air pressure, was used because, as widely recognized, the air pressure is strictly correlated with the wind direction and the wind speed. The color scale has seven fields with $5 \mathrm{hPa}$ steps, from $985 \mathrm{hPa}$ to $1015 \mathrm{hPa}$. Appendix A contains the results, shown in Figure A1 for the center of the Enoshima race area and Figure A2 for the center of the Hayama race area.

From these figures, it is simple to highlight the prevailing direction of the wind direction, characterized by different wind speeds but also by different air pressure. In this way, it is possible, for example, to identify a pattern of $S$ wind with a wind speed included between 5-12 kts and a pattern of SSW wind with a wind speed included between $8-15 \mathrm{kts}$. At the same time, the $\mathrm{S}$ wind pattern is characterized by the high pressure, as usual for the thermal wind in coastal area (ref.: wind pattern 1A-1B-1C in Table 2), while the SSW wind pattern has prevailing points in the ternary plots of low pressure as usual for the situation characterized by gradient wind (ref.: wind pattern 2 in Table 2). Of course, from a strategical point of view, the two situations are completely different because the oscillations change drastically in the situation of the sea breeze compared to the situation of gradient wind.

Table 2. Wind pattern (WP) features.

\begin{tabular}{|c|c|c|c|c|c|c|c|}
\hline $\begin{array}{l}\text { Wind } \\
\text { Pattern }\end{array}$ & Name & $\begin{array}{l}\text { Gradient } \\
\text { Wind } \\
\text { Direction }\end{array}$ & $\begin{array}{c}\text { Gradient } \\
\text { Wind Speed } \\
\text { (kts) }\end{array}$ & $\begin{array}{l}\text { Wind } \\
\text { Direction } \\
\text { Local Shift } \\
\text { (degrees) }\end{array}$ & $\begin{array}{l}\text { Wind Speed } \\
\text { Range (kts) }\end{array}$ & $\begin{array}{c}\text { Air Pressure } \\
\text { (hPa) }\end{array}$ & $\begin{array}{c}\text { Air } \\
\text { Temperature } \\
\left({ }^{\circ} \mathrm{C}\right)\end{array}$ \\
\hline $\begin{array}{c}1 \mathrm{~A}-1 \mathrm{~B}- \\
1 \mathrm{C}\end{array}$ & $\begin{array}{c}\text { Pure Sea Breeze } \\
\text { (fully developed) } \\
\text { Pure Sea Breeze } \\
\text { (not fully } \\
\text { developed) }\end{array}$ & NW-E & $\begin{array}{c}3-9 \\
0-4 \\
9-12\end{array}$ & $\begin{array}{c}80->165-> \\
185->170\end{array}$ & $3-10$ & $1005-><-$ & $26-30$ \\
\hline 2 & $\begin{array}{l}\text { S-SW light with } \\
\text { sea breeze effect }\end{array}$ & S-SW & $1-9$ & $\begin{array}{c}225->185-> \\
195->200\end{array}$ & $5-15$ & $1008 \downarrow$ & $26-30$ \\
\hline 3 & $\begin{array}{c}\text { SW moderate } \\
\text { with rotation to } \\
\mathrm{N}\end{array}$ & SW & $9-14$ & $\begin{array}{c}200->180-> \\
200->360\end{array}$ & $3-12$ & $1010-><-$ & $26-30$ \\
\hline 4 & E-EN moderate & E-NE & $12-18$ & $\begin{array}{c}40->55->80 \\
->90\end{array}$ & $7-10$ & $1005-><-\downarrow$ & $24-32$ \\
\hline 5 & $\begin{array}{l}\text { SW moderate } \\
\text { SW strong }\end{array}$ & S-SW & $\begin{array}{l}10-15 \\
16-25\end{array}$ & $\begin{array}{c}225->195-> \\
200->205\end{array}$ & $10-20$ & 1012 -> 1008 & $26-32$ \\
\hline 6 & $S$ very strong & S-SSW & $26-38$ & $\begin{array}{c}210->195-> \\
200->180\end{array}$ & $10-25$ & $1005 \downarrow$ & $24-28$ \\
\hline
\end{tabular}

The wind patterns are represented by the red circles and the number inside each circle helps to identify them. The blue circles represent the patterns related to cyclone activity, 
which were not examined in this paper. Almost all the wind patterns were overlaid because of the rotation of the wind direction and the rise in the wind speed during the day.

Finally, each wind pattern was associated to the gradient wind extracted by the NOAAGFS model at $925 \mathrm{hPa}$ of height. Table 2 shows the properties of each pattern in detail. The wind patterns can vary during the day, but the precursor of this change is the alteration of the gradient wind. In this case, it is possible to move from one WP to another, looking at Table 1 and the gradient wind, both forecasted and measured, by the wind profile system of the Japan Meteorological Agency (JMA).

Based on this scheme, we performed statistical analysis to verify the validity of the model and we built the first version of the "call book". Subsequently, once we obtained the new data collected in the field during the 2019 summer, we carried out another verification and we updated the DSS with the new results.

\subsection{Verification of Hindcast}

As mentioned before, to conduct the analysis and update the DSS, we used the data observed in the field during summer 2019, more precisely from 3 July to 1 September. The data were collected through weather stations located on seven boats moving around the race area, and recorded continuously, more than one value per minute. In order to compare them with the CALMET output, we needed a single point, representing only one hourly value for the wind speed and direction. At that point, we calculated the geometric barycenter of the displacements of all the boats for each hour, and the average of the speed and direction of the wind.

By way of example, we show the results of the WP 2 analysis. For this pattern, we compared the three days of summer 2019, on which a south-west gradient wind was recorded with the simulated days that showed the same gradient wind, regardless of the date. The results are shown in Tables 3-5.

Table 3. Bias WP 2. The columns indicate the days with the observed data and the rows indicated the days simulated on CALMET.

\begin{tabular}{lcccccc}
\hline & \multicolumn{2}{c}{$\mathbf{0 5 / 0 8 / 2 0 1 9}$} & \multicolumn{2}{c}{$\mathbf{2 0 / 0 8 / 2 0 1 9}$} & \multicolumn{2}{c}{$\mathbf{2 1 / 0 8 / 2 0 1 9}$} \\
\hline & $\begin{array}{c}\text { True Wind } \\
\text { Direction }\end{array}$ & $\begin{array}{c}\text { True Wind } \\
\text { Speed }\end{array}$ & $\begin{array}{c}\text { True Wind } \\
\text { Direction }\end{array}$ & $\begin{array}{c}\text { True Wind } \\
\text { Speed }\end{array}$ & $\begin{array}{c}\text { True Wind } \\
\text { Direction }\end{array}$ & $\begin{array}{c}\text { True Wind } \\
\text { Speed }\end{array}$ \\
\hline $30 / 07 / 2009$ & - & 5.5 & -7.3 & 0.8 & -26.2 & 2.2 \\
$05 / 08 / 2010$ & -17.4 & 10.0 & 5.3 & 5.5 & -15.1 & 6.9 \\
$08 / 08 / 2011$ & -13.6 & 2.6 & 0.6 & -0.7 & -22.1 & 0.8 \\
$30 / 07 / 2012$ & -21.7 & 7.8 & -1.6 & 4.3 & -20.8 & 5.7 \\
$26 / 07 / 2013$ & -29.8 & 6.3 & -10.7 & 1.6 & -32.3 & 2.8 \\
$02 / 08 / 2015$ & -19.9 & 4.7 & -0.5 & -0.5 & -20.9 & 0.4 \\
$06 / 08 / 2015$ & -10.3 & 6.1 & 10.8 & 1.6 & -9.6 & 2.9 \\
$27 / 07 / 2016$ & -15.4 & 6.0 & 0.7 & 2.2 & -19.9 & 3.2 \\
\hline
\end{tabular}

Table 4. MAE WP 2. The columns indicate the days with the observed data and the rows indicated the days simulated on CALMET.

\begin{tabular}{lcccccc}
\hline & \multicolumn{2}{c}{$\mathbf{0 5 / 0 8 / 2 0 1 9}$} & \multicolumn{2}{c}{$\mathbf{2 0 / 0 8 / 2 0 1 9}$} & \multicolumn{2}{c}{$\mathbf{2 1 / 0 8 / 2 0 1 9}$} \\
\hline & $\begin{array}{c}\text { True Wind } \\
\text { Direction }\end{array}$ & $\begin{array}{c}\text { True Wind } \\
\text { Speed }\end{array}$ & $\begin{array}{c}\text { True Wind } \\
\text { Direction }\end{array}$ & $\begin{array}{c}\text { True Wind } \\
\text { Speed }\end{array}$ & $\begin{array}{c}\text { True Wind } \\
\text { Direction }\end{array}$ & $\begin{array}{c}\text { True Wind } \\
\text { Speed }\end{array}$ \\
\hline $30 / 07 / 2009$ & 21.0 & 5.5 & 8.9 & 1.0 & 26.2 & 2.2 \\
$05 / 08 / 2010$ & 17.4 & 10.0 & 10.2 & 5.5 & 15.1 & 6.9 \\
$08 / 08 / 2011$ & 17.3 & 3.3 & 9.3 & 1.1 & 22.1 & 0.8 \\
$30 / 07 / 2012$ & 21.7 & 7.8 & 7.3 & 4.3 & 20.8 & 5.7 \\
$26 / 07 / 2013$ & 29.8 & 6.3 & 12.1 & 1.8 & 32.3 & 2.8 \\
$02 / 08 / 2015$ & 19.9 & 4.7 & 7.4 & 1.2 & 20.9 & 0.7 \\
$06 / 08 / 2015$ & 11.1 & 6.1 & 14.7 & 1.7 & 10.4 & 2.9 \\
$27 / 07 / 2016$ & 15.4 & 6.0 & 9.1 & 2.2 & 19.9 & 3.2 \\
\hline
\end{tabular}


Table 5. PCC WP 2. The columns indicate the days with the observed data and the rows indicated the days simulated on CALMET.

\begin{tabular}{lcccccc}
\hline & \multicolumn{2}{c}{$\mathbf{0 5 / 0 8 / 2 0 1 9}$} & \multicolumn{2}{c}{$\mathbf{2 0 / 0 8 / 2 0 1 9}$} & \multicolumn{2}{c}{$\mathbf{2 1 / 0 8 / 2 0 1 9}$} \\
\hline & $\begin{array}{c}\text { True Wind } \\
\text { Direction }\end{array}$ & $\begin{array}{c}\text { True Wind } \\
\text { Speed }\end{array}$ & $\begin{array}{c}\text { True Wind } \\
\text { Direction }\end{array}$ & $\begin{array}{c}\text { True Wind } \\
\text { Speed }\end{array}$ & $\begin{array}{c}\text { True Wind } \\
\text { Direction }\end{array}$ & $\begin{array}{c}\text { True Wind } \\
\text { Speed }\end{array}$ \\
\hline $30 / 07 / 2009$ & 0.2 & 0.4 & 0.3 & 0.7 & 0.5 & 0.5 \\
$05 / 08 / 2010$ & 0.2 & 0.6 & 0.3 & 0.6 & 0.5 & 0.6 \\
$08 / 08 / 2011$ & 0.3 & -0.4 & 0.1 & 0.4 & 0.3 & 0.7 \\
$30 / 07 / 2012$ & 0.4 & -0.2 & 0.0 & 0.3 & -0.1 & 0.7 \\
$26 / 07 / 2013$ & 0.2 & 0.8 & 0.2 & 0.6 & 0.1 & 0.7 \\
$02 / 08 / 2015$ & 0.3 & 0.7 & 0.2 & 0.6 & 0.2 & 0.6 \\
$06 / 08 / 2015$ & 0.1 & 0.5 & 0.2 & 0.7 & 0.1 & 0.6 \\
$27 / 07 / 2016$ & 0.3 & 0.4 & 0.2 & 0.7 & 0.6 & 0.6 \\
\hline
\end{tabular}

The BIAS showed mixed results, but the average error was in a good range. In fact, as said before, it is not possible to define the baseline scores because this is the first time that this methodology has been applied to sailing sports. Consequently, it is necessary to look at the mean absolute error since that BIAS values close to zero could be a compensation between the positive and negative values.

The results of the MAE confirm that some values close to zero were due to the balance between positive and negative values, but most of the days analyzed presented concordant results to those of the BIAS.

The PCC showed a good correlation for almost half of the days, and the highest values of the index can be found in the wind speed results because, as indicated in Section 2.5.3, the complete correlation is given by a value equal to +1 . Additionally, for wind direction, the correlation can be considered relatively good with a PCC included between 0.0 and 0.6 wind pattern named WP2.

The validation of the model through this analysis helped us in the DSS updating process. Comparing the results of the statistical indices, we could select $27 / 07 / 2016$ as the day that best simulates the reality and used it to represent the WP2 in the last version of the "call book".

\subsection{Data Collection and Presentation}

The last phase of the work encompassed two key steps. The acquisition of the analyzed data and their presentation, through the creation of an effective communication system with all the team members: the decision support service. For this purpose, with the data extracted from the CALMET database, we created tables and graphs showing the trend of the wind speed, wind direction, and atmospheric pressure during the day. Appendix B contains the Figures A3-A5, showing the data of the day selected for WP1A, WP2, and WP5, respectively.

Later on, we developed the wind maps using QGIS software. We represented each cell of the CALMET domain with an arrow, oriented according to the wind direction data. The wind speed data were divided into classes, with an interval of $0.5 \mathrm{kts}$. These maps can be truly helpful in the communication process because they give an immediate image of the wind pattern inside the bay. Figures 5-8 illustrate the wind maps for WP1A; Figures 9-12 for WP2; Figures 13-16 for WP5. 


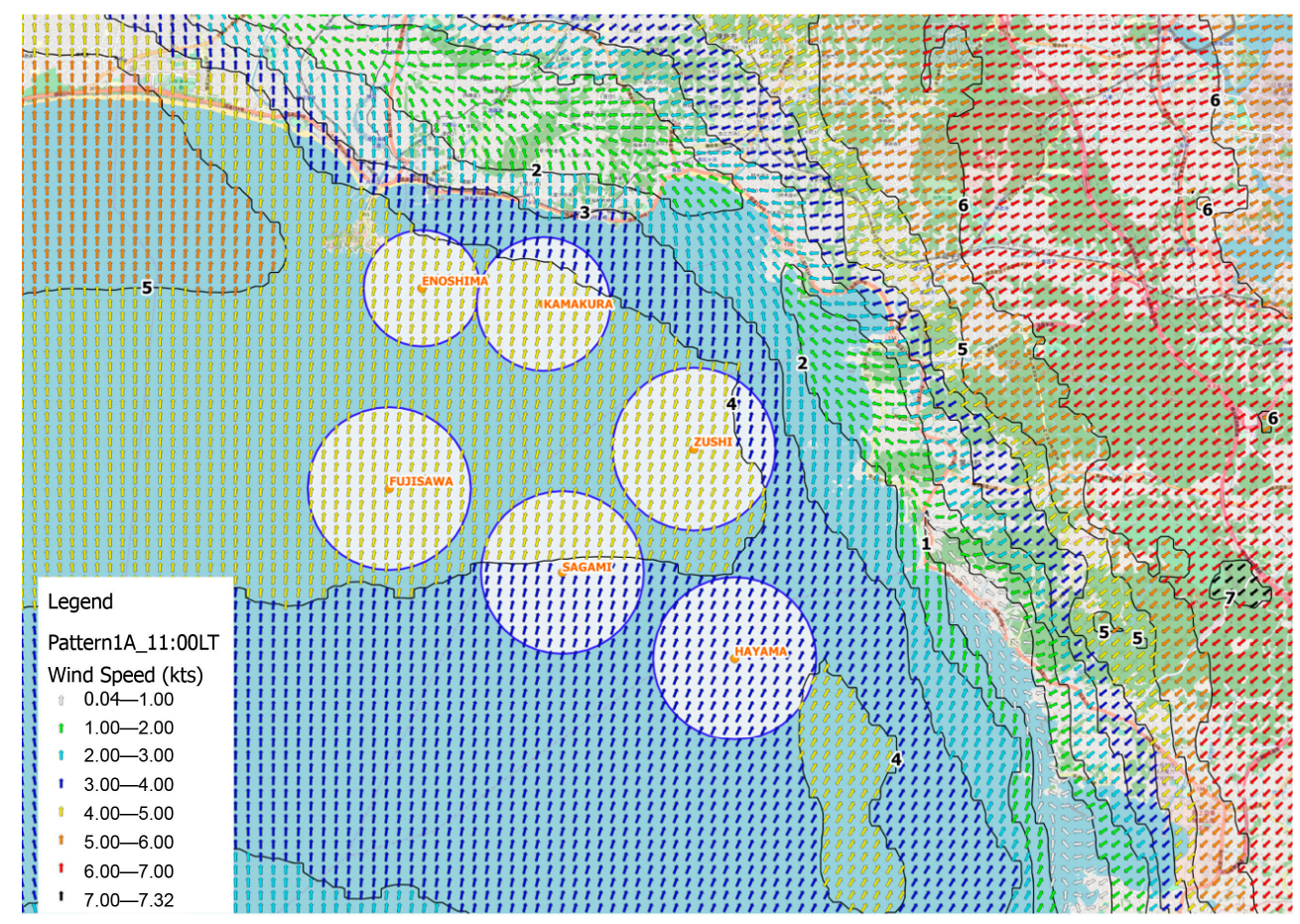

Figure 5. Modeled wind maps of the race fields: WP1A—07.08.2013; 11.00 LT. The arrows represent the wind direction, the colors the speed. The isolines separate areas with different wind speed.

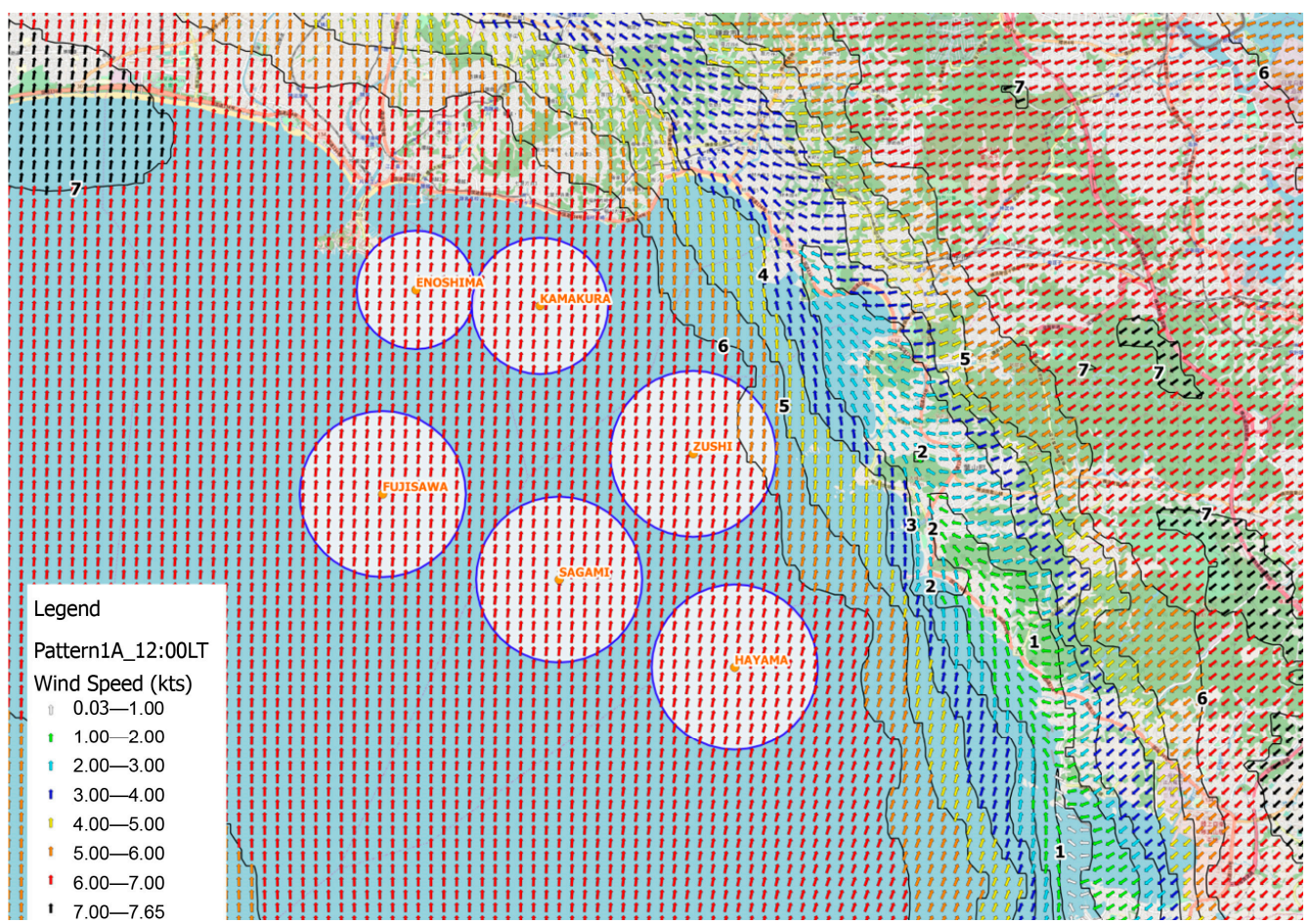

Figure 6. Modeled wind maps of the race fields: WP1A-07.08.2013-12.00 LT. The arrows represent the wind direction, the colors the speed. The isolines separate areas with different wind speed. 


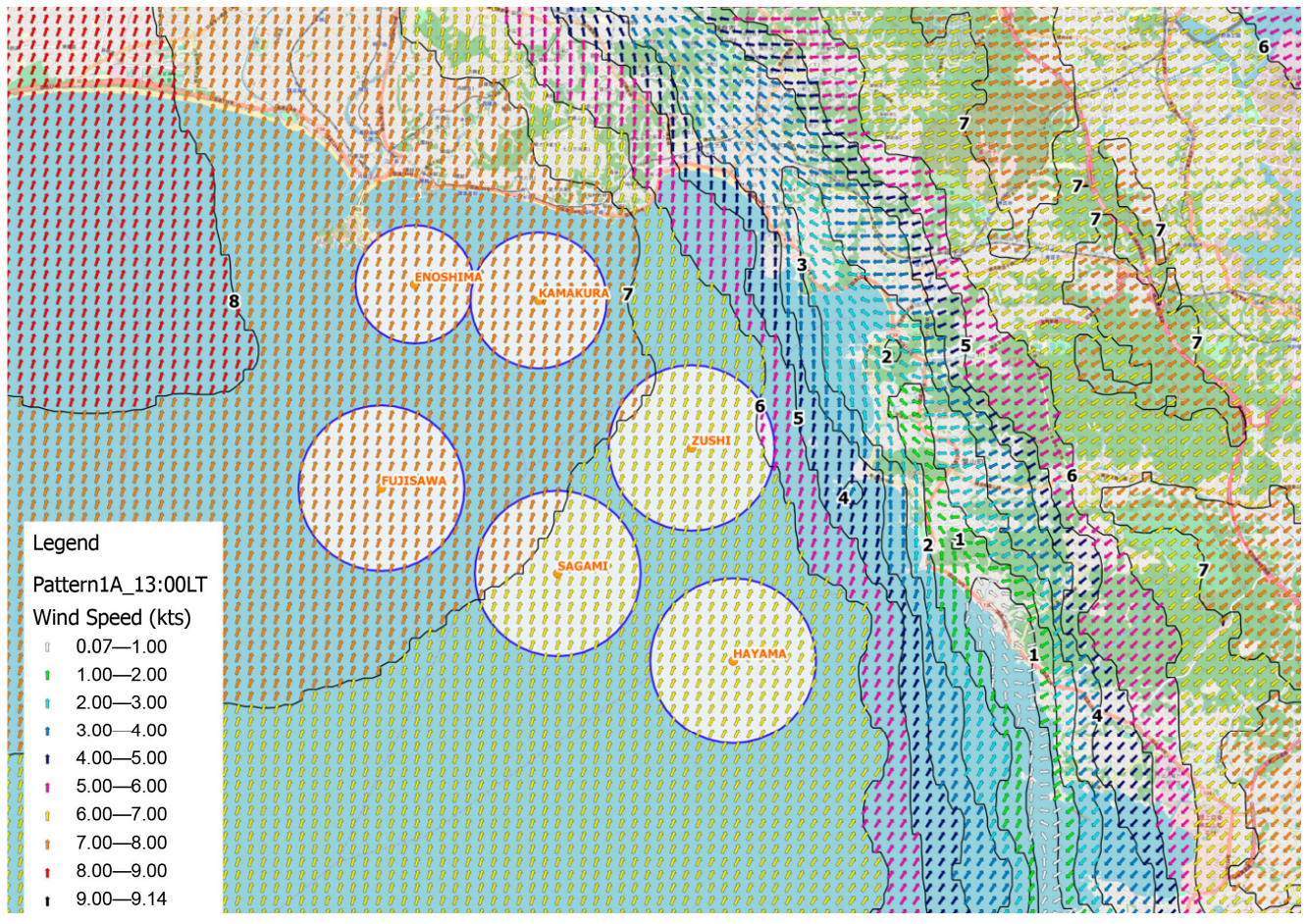

Figure 7. Modelled wind maps of the race fields: WP1A - 07.08.2013; 13.00 LT. The arrows represent the wind direction, the colors the speed. The isolines separate areas with different wind speed.

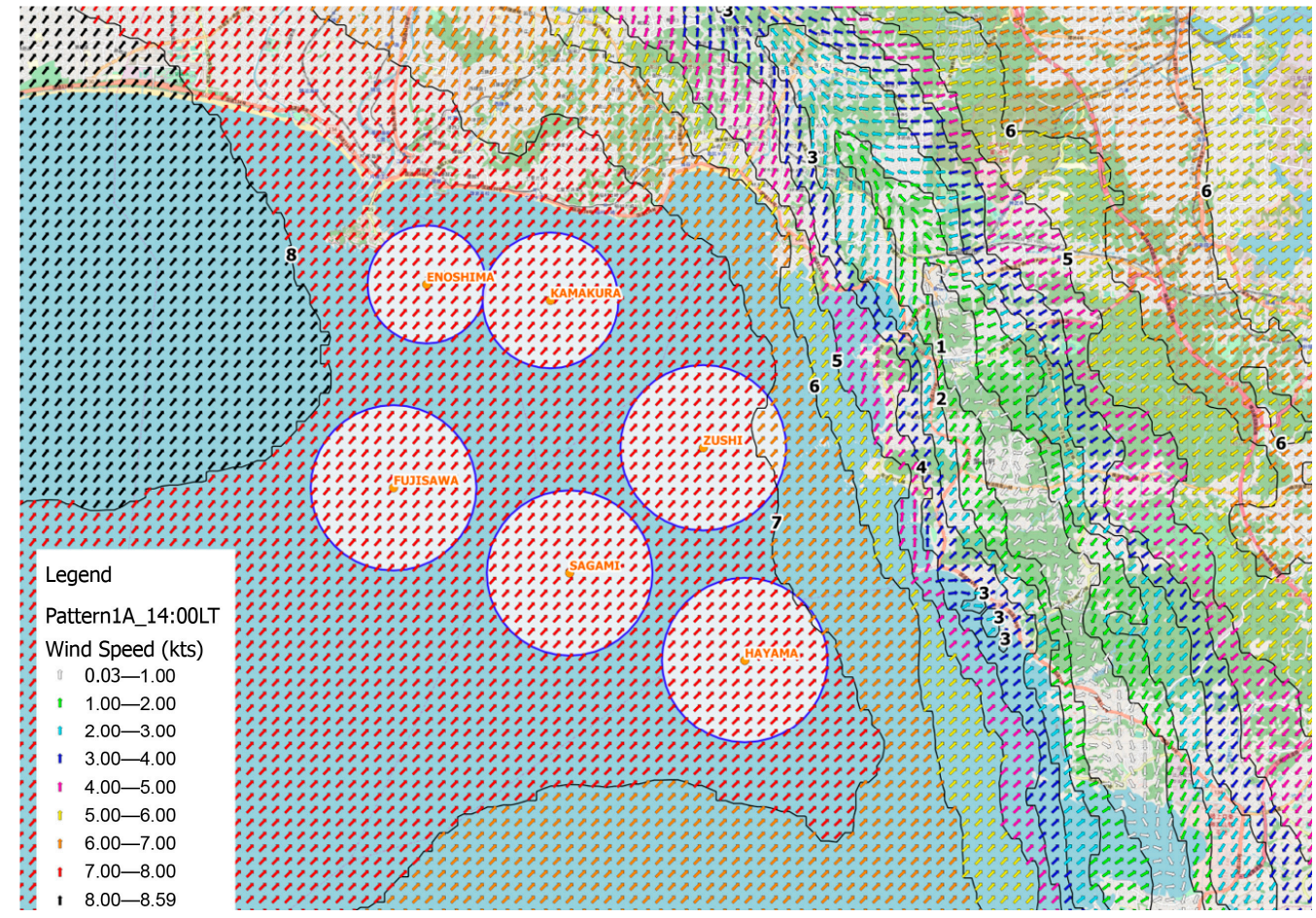

Figure 8. Modeled wind maps of the race fields: WP1A-07.08.2013; 14.00 LT. The arrows represent the wind direction, the colors the speed. The isolines separate areas with different wind speed. 


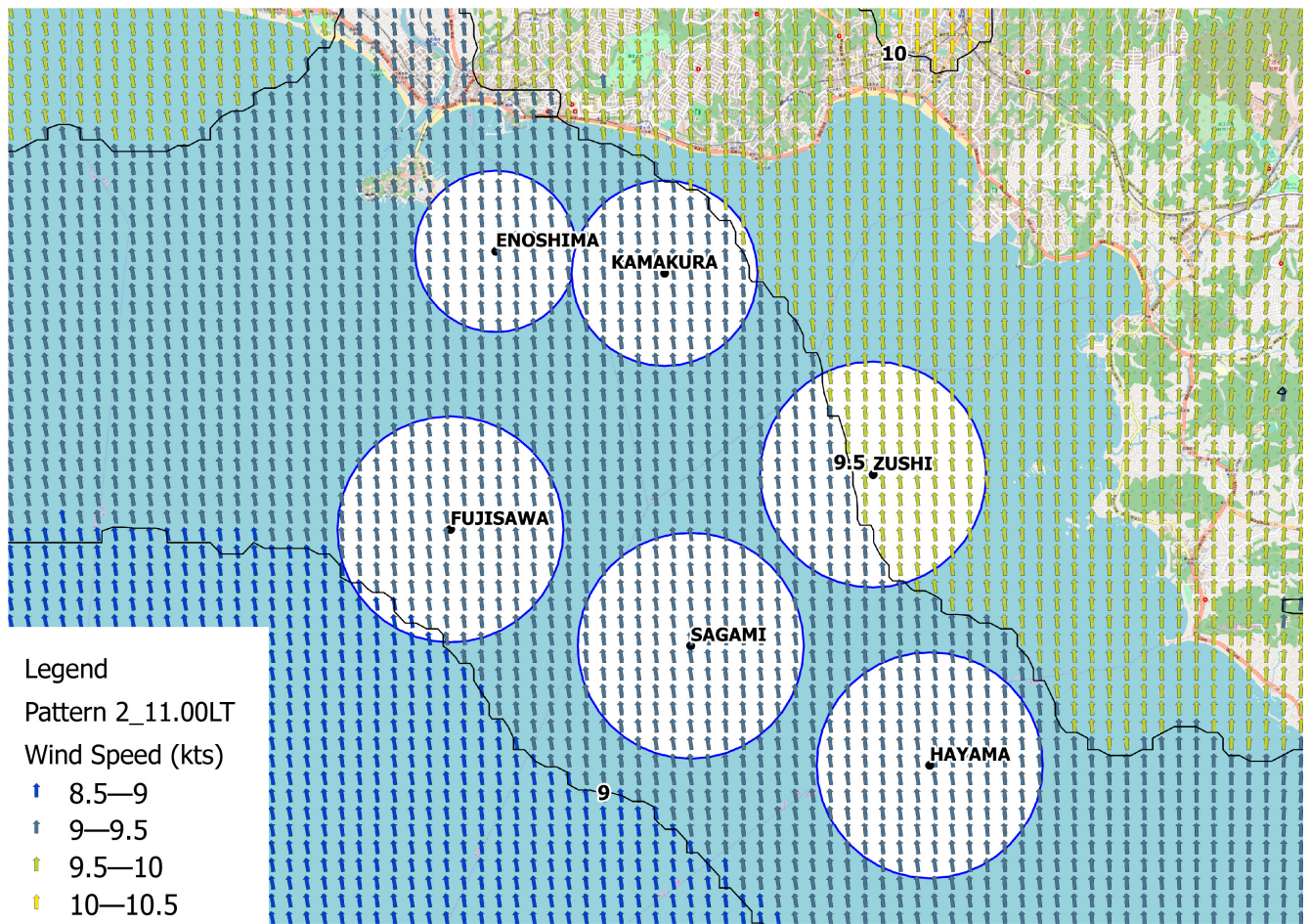

Figure 9. Modeled wind maps of the race fields: WP2-27.07.2016; 11.00 LT. The arrows represent the wind direction, the colors the speed. The isolines separate areas with different wind speed.

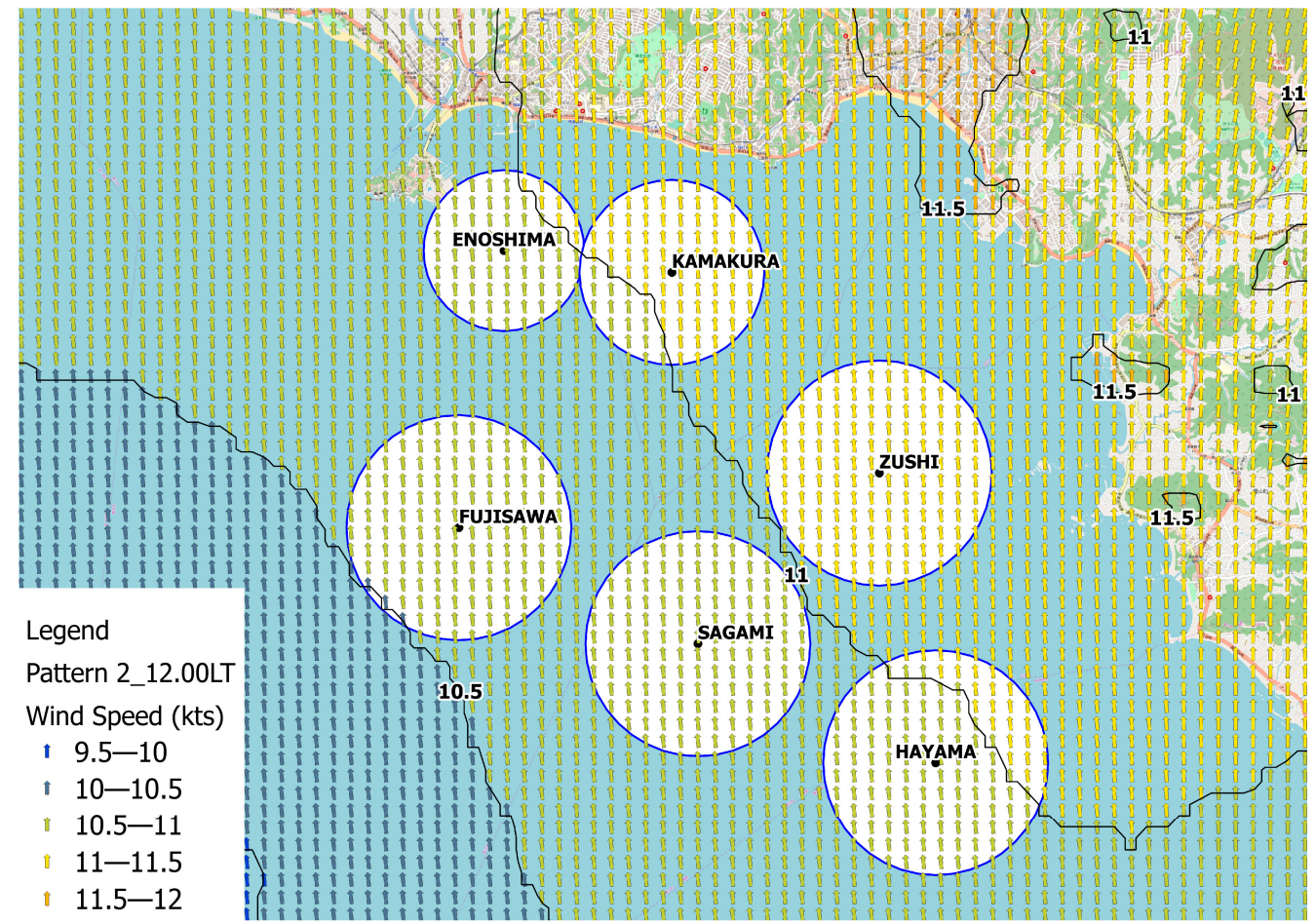

Figure 10. Modeled wind maps of the race fields: WP2-27.07.2016; 12.00 LT. The arrows represent the wind direction, the colors the speed. The isolines separate areas with different wind speed. 


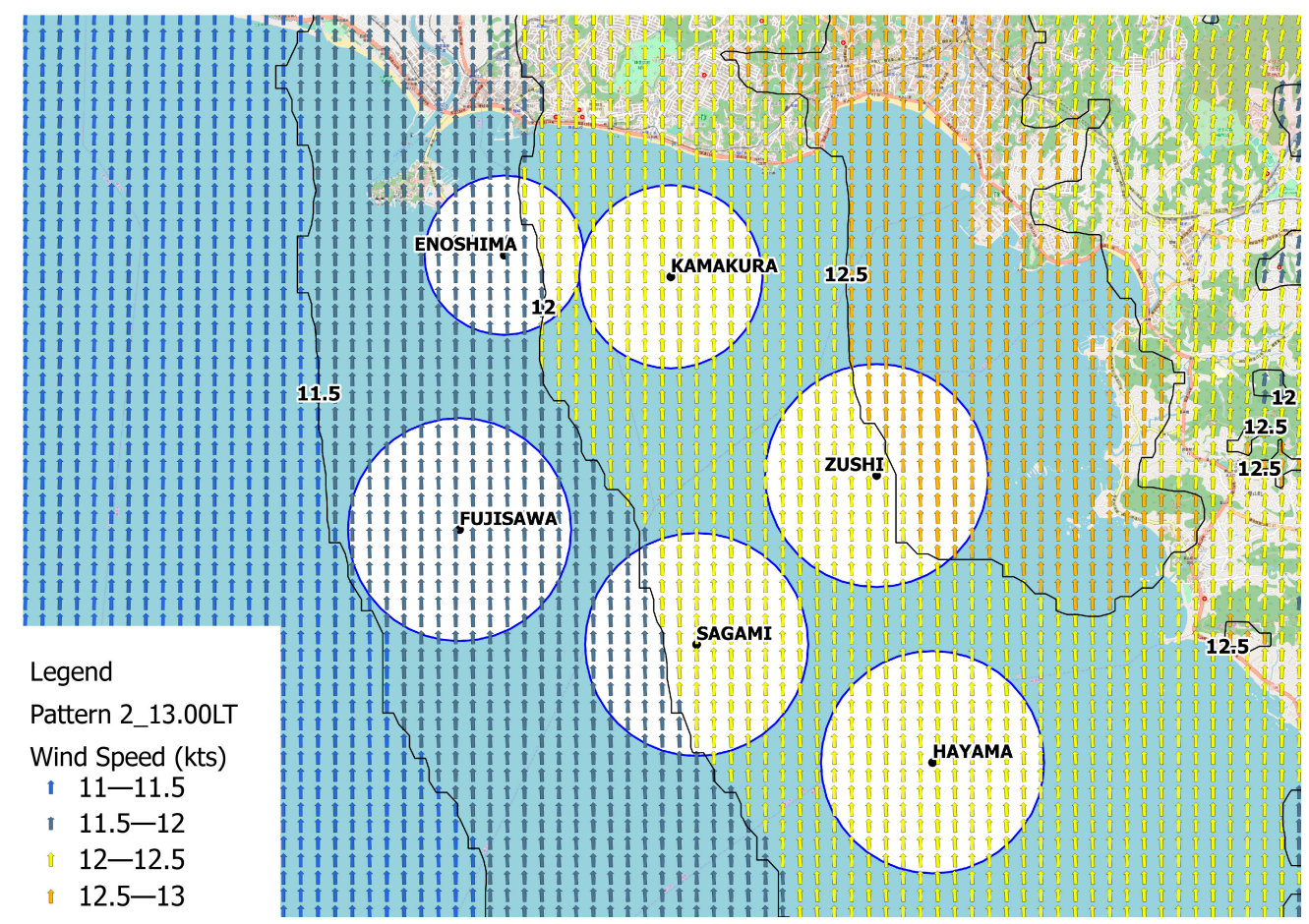

Figure 11. Modeled wind maps of the race fields: WP2-27.07.2016; 13.00 LT. The arrows represent the wind direction, the colors the speed. The isolines separate areas with different wind speed.

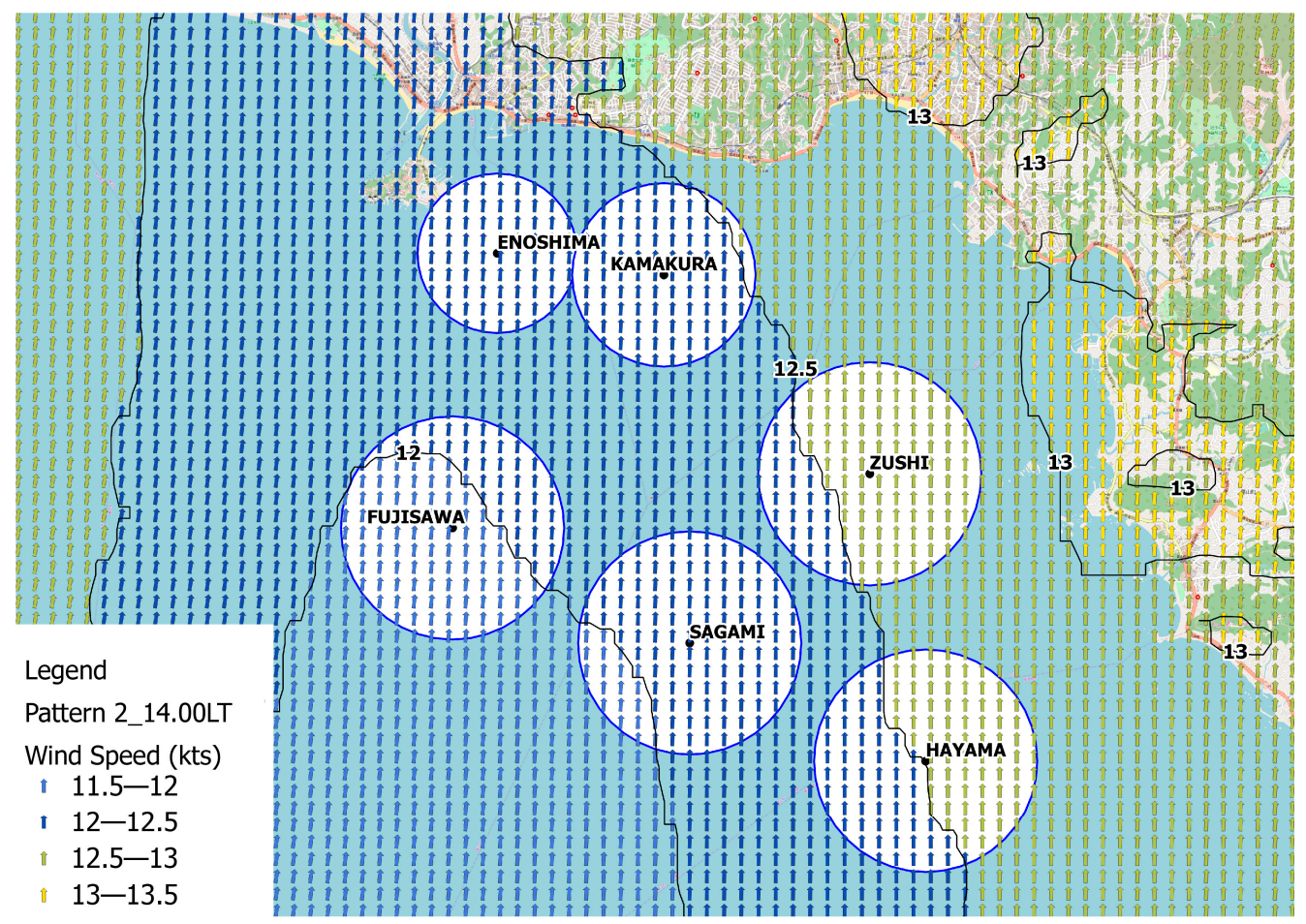

Figure 12. Modeled wind maps of the race fields: WP2-27.07.2016; 14.00 LT. The arrows represent the wind direction, the colors the speed. The isolines separate areas with different wind speed. 


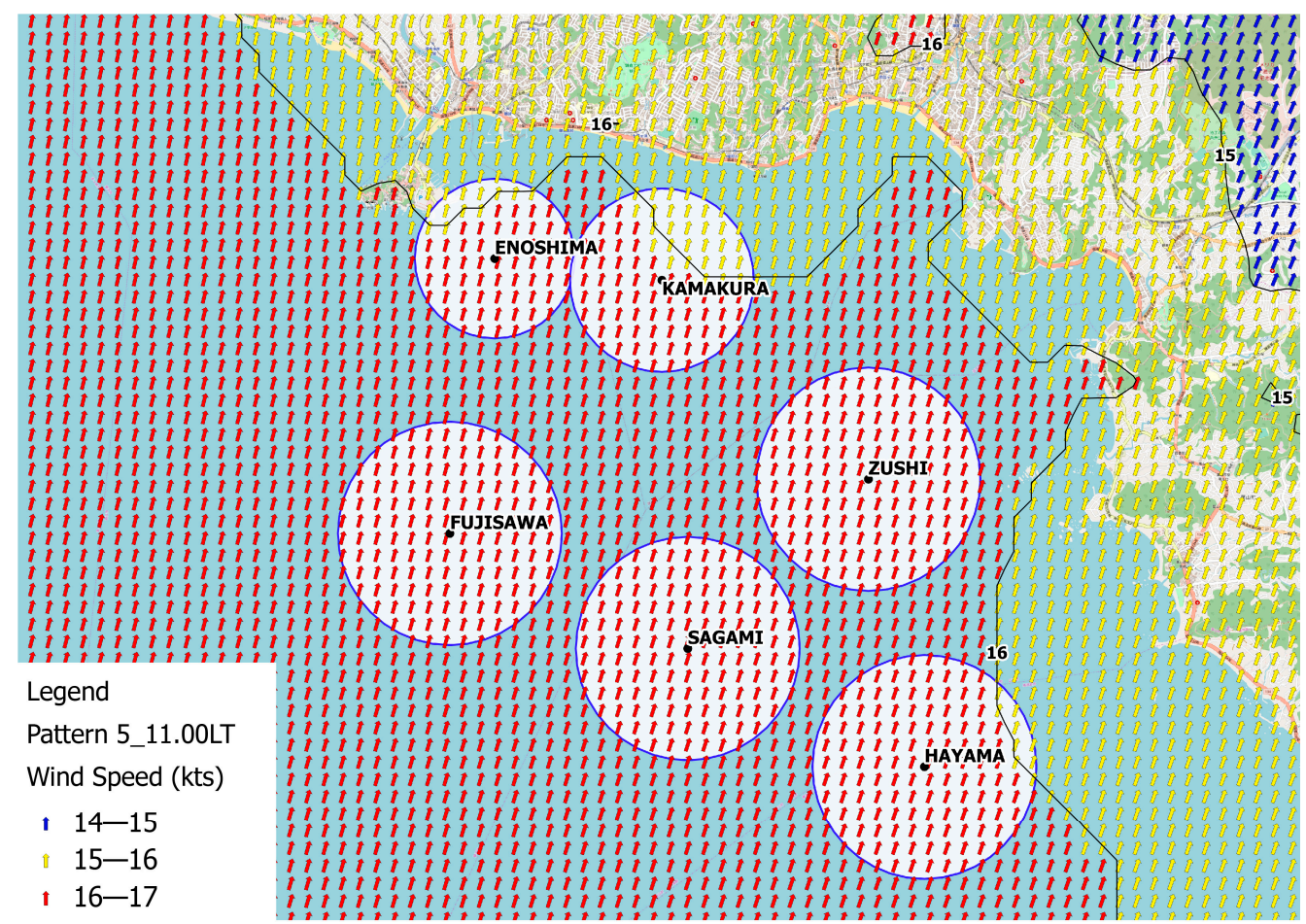

Figure 13. Modeled wind maps of the race fields: WP5-28.07.2010; 11.00 LT. The arrows represent the wind direction, the colors the speed. The isolines separate areas with different wind speed.

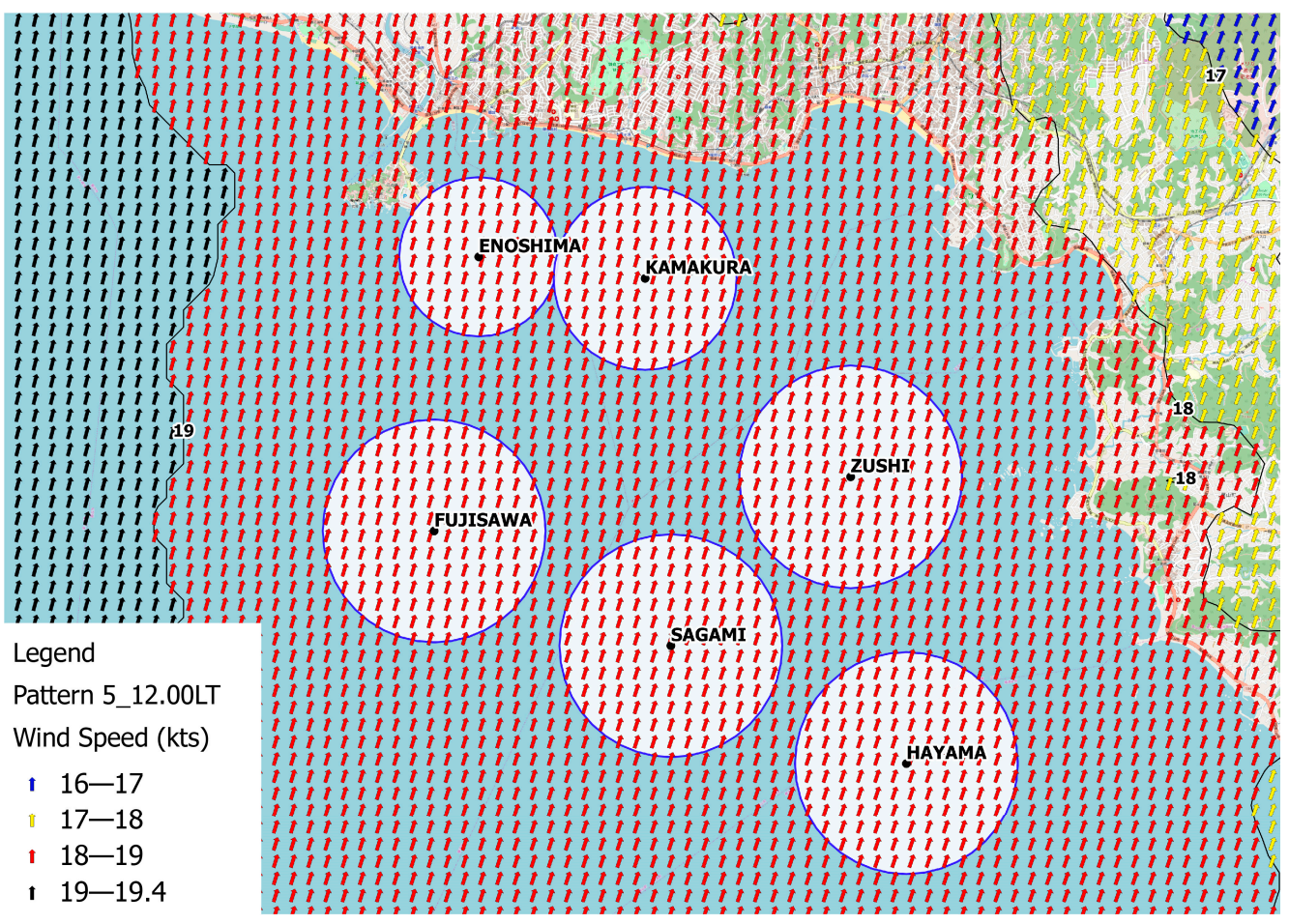

Figure 14. Modeled wind maps of the race fields: WP5-28.07.2010; 12.00 LT. The arrows represent the wind direction, the colors the speed. The isolines separate areas with different wind speed. 


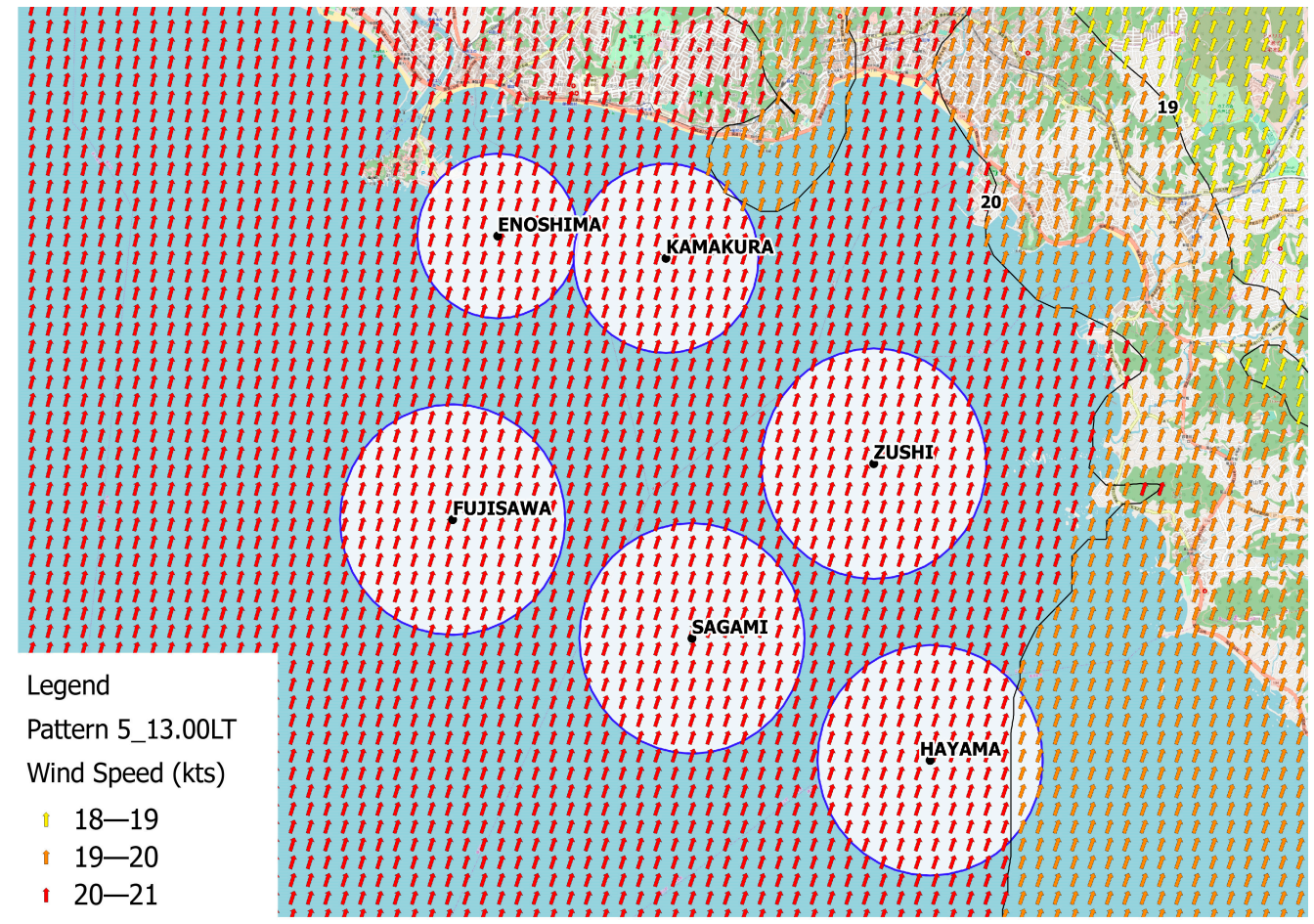

Figure 15. Modeled wind maps of the race fields: WP5-28.07.2010; 13.00 LT. The arrows represent the wind direction, the colors the speed. The isolines separate areas with different wind speed.

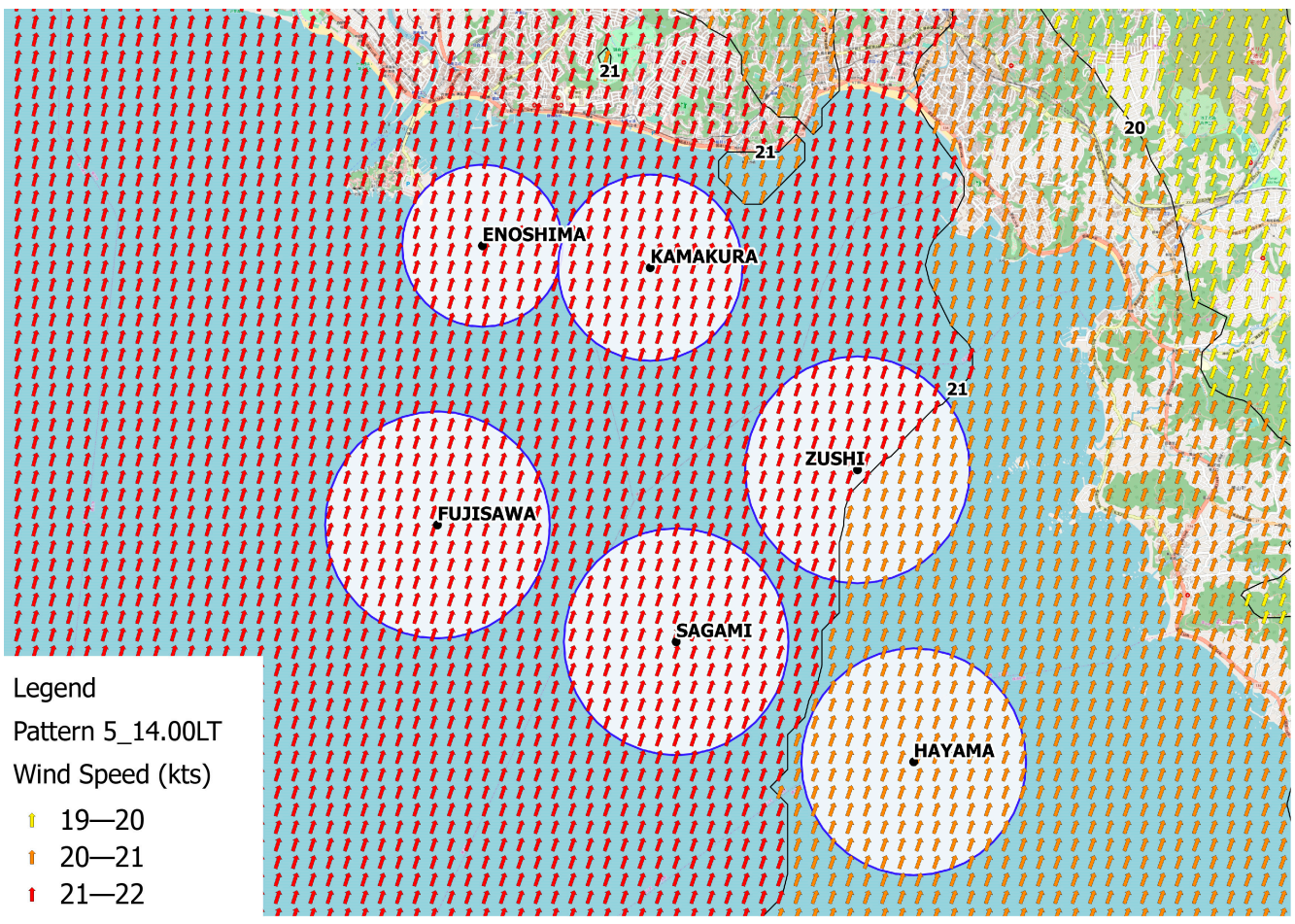

Figure 16. Modeled wind maps of the race fields: WP5-28.07.2010; 14.00 LT. The arrows represent the wind direction, the colors the speed. The isolines separate areas with different wind speed.

Finally, we summarized all the analyzed data into a final table that gives the necessary indications to the athletes on how best to approach the different wind conditions. Tables 6-8 show the tables of WP1A, WP2, and WP5, respectively. 
Table 6. WP1A. Warnings for sailors.

\author{
Gradient wind (1000 m) \\ Wind direction (max. left) \\ Wind direction (max. right) \\ Wind speed (min.) [kts] \\ Wind speed (max.) [kts]
}

Shift

Wind pressure

Wave-Swell

Air temperature (Ta) \& Sea Temperature

Atmospheric pressure

Sky and clouds

Occurrence's frequencies
NE/6-9 kts

180-190 (starting sea breeze around $11.00 \div 12.00 \mathrm{LT}$ )

$160-170$ (at the end of the day)

$$
\text { 225-235 }
$$

$5-6$ (starting sea breeze around $11.00 \div 12.00 \mathrm{LT}$ )

10-12 (at the end of the day)

After the FIRST SHIFT (BACKING if the wind direction will be more right than 180-190 or VEERING if the wind direction will be more left than 180-190), expected around 12.00LT, the wind will VEERING to reach the maximum right (expected around 15.00LT), then it will be BACKING.

ATTENTION 1: During the VEERING and the BACKING, the wind will be OSCILLATING (in the start period of the sea breeze around 12.00LT: period around $5^{\prime}-10^{\prime}$ with angle between $002^{\circ}-005^{\circ}$; after 14.00-15.00LT: the oscillations will be bigger in period, $10^{\prime}-15^{\prime}$, and in angle around $005^{\circ}-008^{\circ}$, max. $010^{\circ}$ ).

ATTENTION 2: The wind speed will increase all days both in VEERING and BACKING

When the sea breeze starting and for all day (both in VEERING and BACKING), the good pressure will be on the right hand side.

SSW wind-wave with possible SW swell $\mathrm{Ta}=26 \div 30^{\circ} \mathrm{C}$ (increasing)

$\mathrm{Ts}=25 \div 26^{\circ} \mathrm{C}\left(\min .23^{\circ} \mathrm{C}\right.$; $\left.\max .28^{\circ} \mathrm{C}\right)$

Increasing in the morning, then steady and finally decreasing from the early afternoon.

Clear with good visibility in the morning, then cumulus $(\mathrm{Cu})$ steady inland. 40.6\% (together with WP1_B and WP1_C)

Table 7. WP2. Warnings for sailors.

\author{
Gradient wind (1000 m) \\ Wind direction (max. left) \\ Wind direction (max. right) \\ Wind speed (min.) [kts] \\ Wind speed (max.) [kts]
}

Shift

Wind pressure

Wave-Swell

Air temperature (Ta) \& Sea Temperature

(Ts)

Atmospheric pressure

Sky and clouds

Occurrence's frequencies
S-SW /1-9kts

160-170 (with the minimum of the wind speed included between 5-7 kts)

170-180 (with the minimum of the wind speed included between $5-7 \mathrm{kts}$ ) $220-230$

5-6

A significant measure of the minimum of the wind speed will be around $12.00 \mathrm{LT}$

$$
11-13
$$

LEFT trend until $12.00 \div 13.00 \mathrm{LT}$, then RIGHT trend in OSCILLATING wind (long oscillations, more or less $10^{\prime}-20^{\prime}$ as the persistent shifts, with big angle included between $020^{\circ}-040^{\circ}$. It will be very difficult to find an average direction due to the long period of the oscillations).

ATTENTION FOR THE OSCILLATIONS: Danger! It is very difficult to know the period of the oscillations, so it is very difficult to be well positioned in function of the oscillations. We do not have "secondary" OSCILLATIONS to help us to return if we are on the wrong side. You have to be careful!

Zushi better pressure in left hand side; Sagami possible better on left hand side (it depends on the strength of the wind speed); in other race areas, better in the middle right but, sometimes the pressure follows the shift. SW

$\mathrm{Ta}=26 \div 30^{\circ} \mathrm{C}$ (increasing)

$$
\mathrm{Ts}=25 \div 26^{\circ} \mathrm{C}\left(\min .23^{\circ} \mathrm{C} ; \max .28^{\circ} \mathrm{C}\right)
$$

Decreasing

Partially cloudy with milky sky and bad visibility.

Stratocumulus (Sc) and $\mathrm{Cu}$ clouds in race area. $31.8 \%$ 
Table 8. WP5. Warnings for sailors.

\author{
Gradient wind (1000 m) \\ Wind direction (max. left) \\ Wind direction (max. right) \\ Wind speed (min.) [kts] \\ Wind speed (max.) [kts]
}

Shift

Wind pressure

Wave-Swell

Air temperature (Ta) \& Sea

Temperature (Ts)

Atmospheric pressure

Sky and clouds

Occurrence's frequencies

\section{SW/10-15 kts (moderate) \\ SW/16-25 kts (strong) \\ 180-190}

220-230 (early morning or in the start of the pattern)

200-210 (late afternoon or in the end of the pattern)

$$
\text { 10-11 }
$$

20-25 G 30

First trend to the LEFT (with increasing wind speed). Then, when the wind speed is above 14-15kts, OSCILLATING wind (oscillations, more or less $5^{\prime}-20^{\prime}$ as the persistent shifts, with the angle included between $010^{\circ}-020^{\circ}$. It will be very difficult to find an average direction due to the long period of the oscillations) with slight RIGHT trend in the end of the day. ATTENTION FOR THE OSCILLATIONS: Danger! It is very difficult to know the period of the oscillations, so it is very difficult to be well positioned in function of the oscillations. We do not have "secondary" OSCILLATIONS to help us to return if we are on the wrong side. You have to be careful!

ATTENTION FOR THE STRATEGY 1: If you start at 12.00LT, a good side will be the middle left for the first shift and the good pressure from left. If you start later (from 13.00 to

16.00LT), the situation will be OPEN. The best solution is sailing fast in the center of the race area (middle right can be favored but also middle left is safe). AVOID THE CORNER! ATTENTION FOR THE STRATEGY 1: In the Fujisawa race area, the increasing wind speed (from 11-12 kts to 16-17 kts) or in decreasing wind speed (from 18-19 kts to 11-12 kts), the best side is the left for the pressure and for the left hand shift of the wind in the top-mark (left wind in the top-mark comparing to the start line). In this case, YOU CAN SAIL HARD IN THE CORNER!

In the first moment, when the wind speed increases up to 13-15 kts and shift left, the good pressure is in the left hand side, then the good pressure gradually moves to the off-shore race area and in the right hand side for Zushi and Hayama. In other race areas (excluding Fujisawa), the pressure is almost the same forboth for right and left hand side. In Fujisawa, it is better on the left hand side.

SW wind-wave and swell

$\mathrm{Ta}=26 \div 32^{\circ} \mathrm{C}$ (increasing)

$\mathrm{Ts}=25 \div 26^{\circ} \mathrm{C}\left(\min .23^{\circ} \mathrm{C} ; \max .28^{\circ} \mathrm{C}\right)$

Decreasing

Partially cloudy-cloudy with front moving on the race area or clear partially cloudy with medium visibility and $\mathrm{Cu}$, Cumulonimbus $(\mathrm{Cb})$, steady inland and along the coastal line in the afternoon $10.2 \%$

These tables were generated using the information derived from the results of the CALMET model and starting from the gradient wind extracted by the NOAA-GFS gradient wind. It is evident, looking at Figures 5-16, how we can summarize in "metacommunication" called "wind's pressure" the distribution of the wind speed in the different race area. At the same time, the analysis of the CALMET results in the different time slot helps to generate an abstract of the wind's shifts that are crucial for the strategical decision.

Finally, considering all the possible information that can be extracted from the wind patterns tables (i.e., trend of the atmospheric pressure and difference between air temperature and sea temperature), it is possible to have a more detailed analysis of the oscillations patterns that cannot be shown by the results of the CALMET model.

Once all the data were updated and organized in plots, tables, and maps, we could finally build the new version of the "call book". These kinds of instruments are essential in the preparation of competitions since they represent the connection between scientific research and sports performance.

\section{Discussion}

The methodology developed in this research provides an in-depth knowledge of the meteorological variables, and in sports where these variables have a strong influence such as sailing, it can help athletes to prepare a race strategy. This method is divided into three 
main steps, and the outcome can give a significant advantage during competitions to the athletes who apply it.

First, a simulation was run through a NWP system to reconstruct a database of weather conditions in the selected area. For this study, we chose the WRF and CALMET models, whose combined use has proven to be one of the most effective tools in forecasting meteorological variables. One advantage of these models is that they can run almost in real time, between 12 and $24 \mathrm{~h}$ before the event. Thereafter, the WP of the day will be determined by comparing the gradient wind, predicted and observed, by the JMA wind profiler.

The second step concerns the analysis of the data extracted from the database. Initially, we used the simulated data to reconstruct the most frequent wind patterns inside the bay; then we tested the model, comparing the simulated data with those collected in the field. The results of the statistical analysis-performed by means of BIAS, MAE, and PCC-also allowed us to identify the simulated days with the highest level of accuracy, which were used for the creation of wind maps on QGIS.

Finally, the data are presented and communicated. The tool through which this last phase is carried out is the "call book", a guide that provides, for each pattern, data and information concerning all the relevant meteorological variables, in a clear and synthetic way. This tool is used by the coaches during training as a decision support service to prepare the regatta strategy, but it can also be very useful on the race day, when compared to the short-term weather forecast, to know in advance the developments of the weather conditions.

During the Olympic Test Event held in Enoshima in August 2019, the "call book" was used to prepare the forecasts and to decide the race strategies for the Swedish Sailing Olympic Team. The results obtained by the Team (one gold medal in Laser class and one silver medal in 470 class), together with a re-analysis conducted with the data measured by the SAP system (https: / / www.sapsailing.com/gwt/Home.html\#/event/:eventId=63 89fb9d-12e1-47ef-9831-ddab8cf9598f, last access: 11 May 2021), showed for us that the "call book" had a higher reliability estimated around $80 \%$. This analysis indicated that the applied methodology can be considered robust, considering the limitation that the results of the model have to be summarized in a single table. In the case of complex topography and considering that the races are in different areas, an abstract of the information in a single table can generate a loss of information. Of course, to minimize this risk, a continuous feedback between athletes, coaches and meteorologist is very important as we applied it to build the presented "call book".

Finally, the results show how a methodology, utilized in other research areas, can be considered innovative in the sport field. At the same time, it is interesting to observe that climatic analysis can be extended to an unusual application, which is the sport industry. Moreover, it is important to observe that this methodology can be applied to study the climatic conditions of the coastal area regarding the management of offshore works.

\section{Conclusions}

In this research, the recurring weather conditions inside Enoshima Bay in Japan were analyzed. The time-period examined was the one in which the 2020 Tokyo Olympics were supposed to take place from 24 July to 9 August. This analysis is part of a wider system that, through scientific research, aims to improve the sports performance of athletes. This paper focused on sailing competitions, but the same methodology can be applied to other sports.

Through the CALWRF processor, a combined simulation of the WRF and CALMET models was launched, thanks to which we built an offshore database of the recent 10-year period, from 2009 to 2018. From this dataset, we extracted, in the time interval that goes from 9.00LT to $18.00 \mathrm{LT}$, data of wind direction and wind speed at $10 \mathrm{~m}$ above sea level. Furthermore, we extracted the air temperature and density near the ground to estimate the atmospheric pressure employed to build the ternary plots and identify the wind patterns. 
The CALMET output was processed with WindRose PRO3 software to classify the different wind behavior scenarios according to wind speed and direction. At the beginning, we created wind roses for all race fields, which showed a similar behavior: prevailing wind direction from S and SSW and a constant increase in speed during the day. Afterward, we constructed the ternary plots, comparing wind speed and direction and atmospheric pressure; this allowed us to identify six distinct patterns.

Once the wind patterns were established, we conducted a climatological analysis using NOAA data to select the days that best fit the pattern perimeters. From this analysis, we selected and extracted from the CALMET database 32 days, on which the model verification was carried out. The comparison between the data extracted from CALMET and those observed during the summer of 2019 was performed, applying three statistical indexes: BIAS, MAE, and PCC.

The results of the statistical analysis demonstrated the high reliability of the model in predicting wind behavior. On the day selected to represent the WP2, the average error of wind direction was around 14 degrees, while the average error of wind speed was below $4 \mathrm{kts}$; the average PCC value was about 0.4 for the wind direction 0.6 for the speed. We reiterated this type of analysis for each pattern, always selecting the day that produced the best results. With the data of the selected days, we created the wind maps, graphs, and tables to fill the "call book", the final guide with highly detailed information needed by sailors.

This method brings two elements of great innovation to this research area: the use of historical data, simulated with CALMET, as climate data and its capacity for continuous improvement by correcting past mistakes.

This is a completely new system and future research needs to improve it. For example, the quality of the weather database might be improved by adding the measurements of weather stations, with nudging techniques in WRF, or directly in CALMET as surface stations; moreover, the verification of hind-cast could be integrated with other statistical models.

In addition, this analysis might be applied to other research fields. For instance, we believe that the knowledge of the wind patterns could be valuable in studying climate change effects in marine and coastal area to design the best adaption and mitigation initiatives.

Author Contributions: Conceptualization, A.P., R.B.(Roberto Bellasio) and P.M.; Methodology, P.M., A.P., R.B. (Roberto Bellasio), R.B. (Roberto Bianconi) and A.B.; Modeling, R.B. (Roberto Bellasio) and R.B. (Roberto Bianconi); Validation, P.M., A.P., R.B. (Roberto Bellasio) and A.B.; Formal analysis, A.P. and P.M.; Graphical analysis (QGIS), P.M., A.P. and A.B.; Writing-original draft preparation, P.M., A.P. and R.B. (Roberto Bellasio); Writing-review and editing, A.P., R.B. (Roberto Bellasio) and A.B.; Supervision, A.P.; Project management, A.P. All authors have read and agreed to the published version of the manuscript.

Funding: This research received no external funding.

Acknowledgments: The authors acknowledge the Swedish Sailing Federation for the support to the presented research.

Conflicts of Interest: The authors declare no conflict of interest. 


\section{Appendix A}

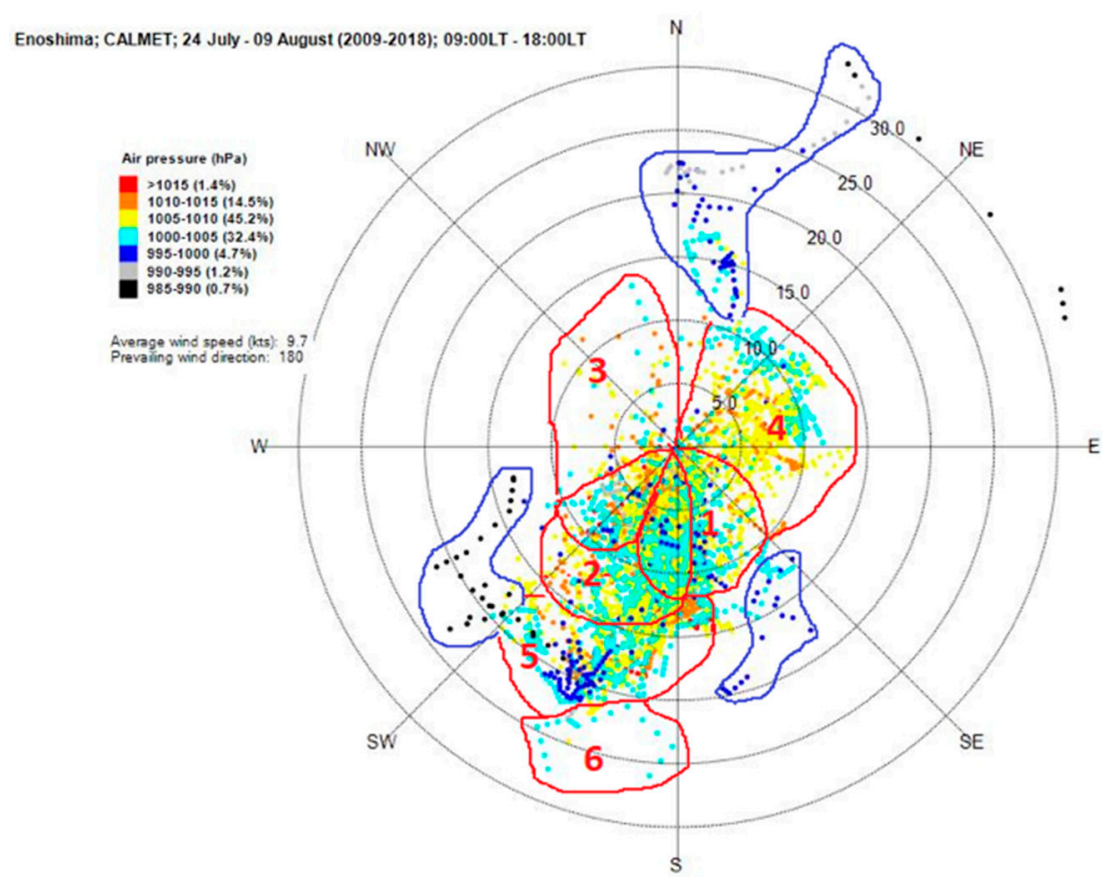

Figure A1. Ternary plot with wind direction (deg), wind speed (kts), and air pressure (hPa) for the Enoshima race area generated by CALMET. Time interval 09:00LT-18:00LT, period 24 July-9 August, years 2009-2018.

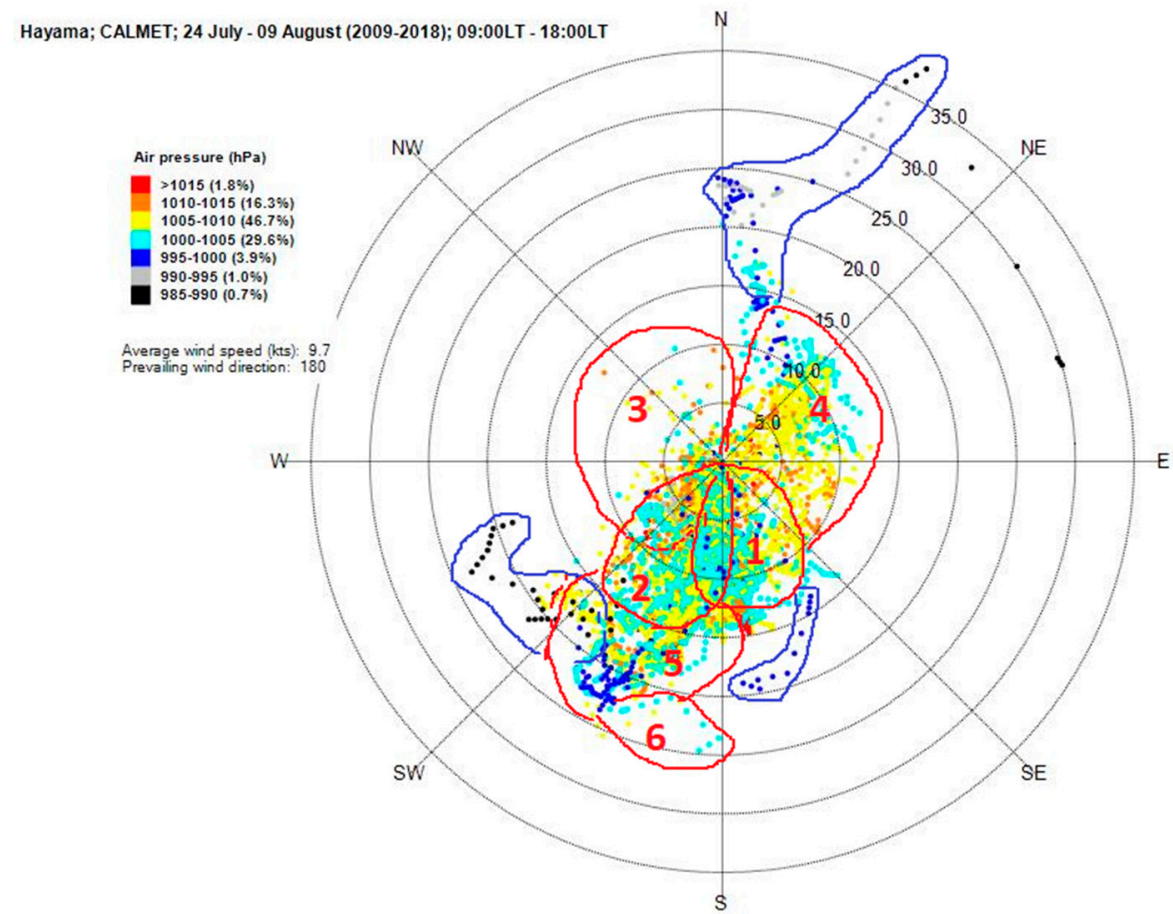

Figure A2. Ternary plot with wind direction (deg), wind speed (kts), and air pressure (hPa) for the Hayama race area generated by CALMET. Time interval 09:00LT-18:00LT, period 24 July-9 August, years 2009-2018. 
Appendix B

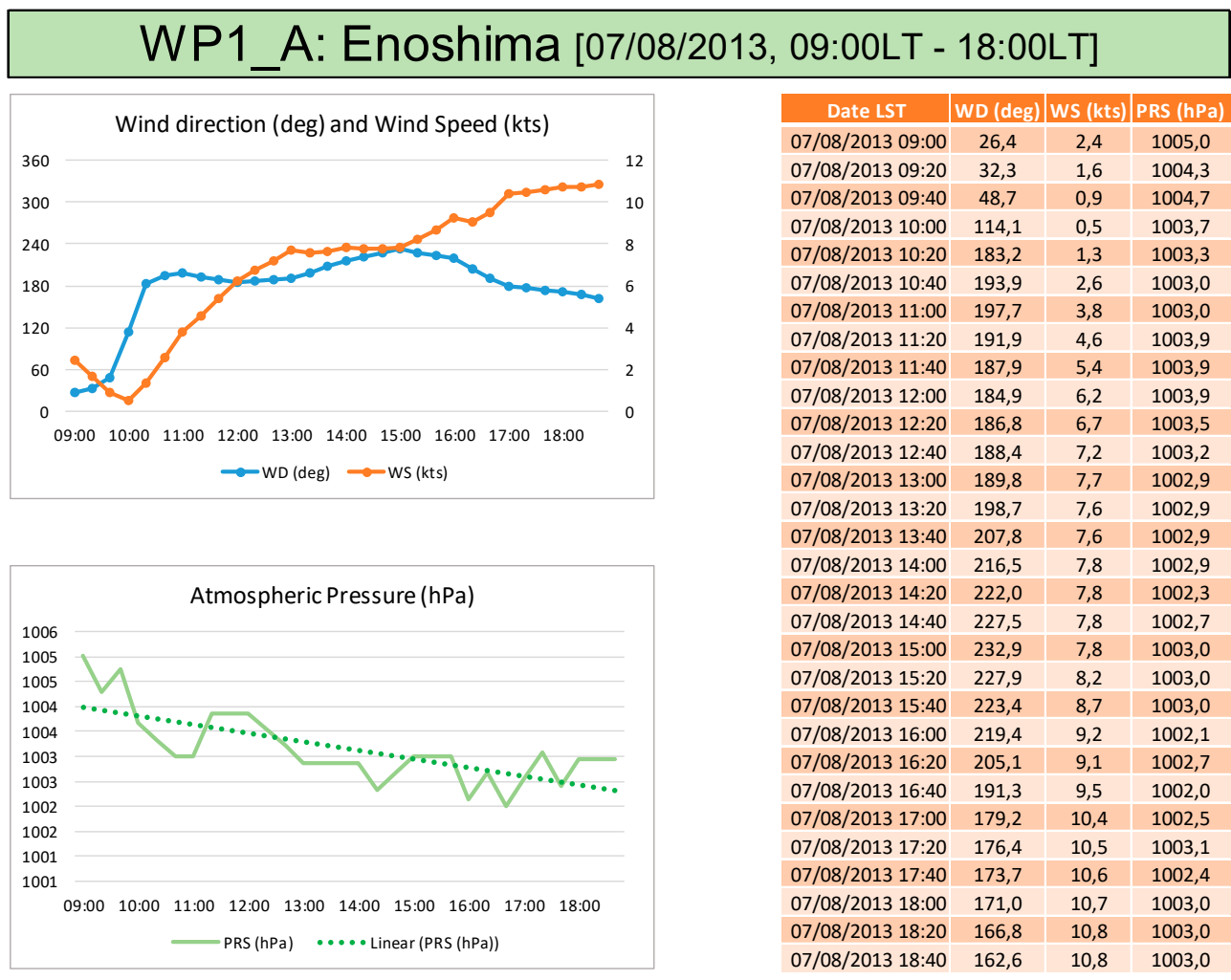

\section{WP1_A: Hayama [07/08/2013, 09:00LT - 18:00LT]}

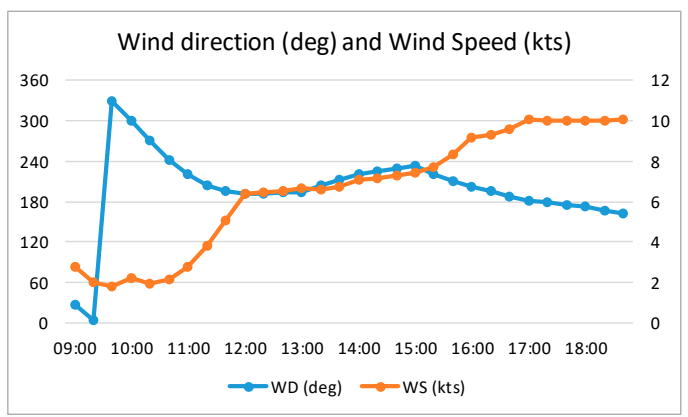

\begin{tabular}{|c|c|c|c|}
\hline Date LST & WD (deg) & WS (kts) & PRS (hPa) \\
\hline $07 / 08 / 2013$ 09:00 & 27,0 & 2,7 & 1005,6 \\
\hline $07 / 08 / 2013$ 09:20 & 5,0 & 2,0 & 1005,0 \\
\hline $07 / 08 / 2013$ 09:40 & 329,7 & 1,8 & 1004,8 \\
\hline $07 / 08 / 201310: 00$ & 298,9 & 2,3 & 1003,4 \\
\hline $07 / 08 / 201310: 20$ & 270,7 & 1,9 & 1003,7 \\
\hline $07 / 08 / 201310: 40$ & 240,6 & 2,1 & 1004,1 \\
\hline $07 / 08 / 201311: 00$ & 220,3 & 2,8 & 1003,5 \\
\hline $07 / 08 / 201311: 20$ & 204,6 & 3,8 & 1003,2 \\
\hline $07 / 08 / 201311: 40$ & 196,1 & 5,1 & 1003,2 \\
\hline $07 / 08 / 201312: 00$ & 191,1 & 6,4 & 1003,2 \\
\hline $07 / 08 / 201312: 20$ & 192,1 & 6,5 & 1003,2 \\
\hline $07 / 08 / 201312: 40$ & 193,0 & 6,5 & 1003,2 \\
\hline $07 / 08 / 201313: 00$ & 194,0 & 6,6 & 1003,5 \\
\hline $07 / 08 / 201313: 20$ & 203,4 & 6,6 & 1003,2 \\
\hline $07 / 08 / 201313: 40$ & 212,7 & 6,7 & 1003,2 \\
\hline $07 / 08 / 201314: 00$ & 221,3 & 7,1 & 1002,3 \\
\hline $07 / 08 / 201314: 20$ & 225,3 & 7,1 & 1002,7 \\
\hline $07 / 08 / 201314: 40$ & 229,2 & 7,3 & 1003,0 \\
\hline $07 / 08 / 201315: 00$ & 232,9 & 7,4 & 1002,1 \\
\hline $07 / 08 / 201315: 20$ & 221,2 & 7,7 & 1002,7 \\
\hline $07 / 08 / 201315: 40$ & 210,7 & 8,3 & 1002,3 \\
\hline $07 / 08 / 201316: 00$ & 201,9 & 9,1 & 1002,5 \\
\hline $07 / 08 / 201316: 20$ & 194,9 & 9,3 & 1002,2 \\
\hline $07 / 08 / 201316: 40$ & 188,2 & 9,6 & 1002,8 \\
\hline $07 / 08 / 201317: 00$ & 182,0 & 10,0 & 1002,4 \\
\hline $07 / 08 / 201317: 20$ & 178,6 & 10,0 & 1003,0 \\
\hline $07 / 08 / 201317: 40$ & 175,2 & 10,0 & 1003,8 \\
\hline $07 / 08 / 201318: 00$ & 171,8 & 10,0 & 1003,5 \\
\hline $07 / 08 / 201318: 20$ & 167,5 & 10,0 & 1003,5 \\
\hline $07 / 08 / 201318: 40$ & 163,2 & 10,1 & 1003,5 \\
\hline
\end{tabular}

Figure A3. WP1A, Enoshima and Hayama race field, 07/08/2013. Wind speed and direction and atmospheric pressure data extracted and simulated on CALMET. 
WP2: Enoshima [27/07/2016, 09:00LT - 18:00LT]

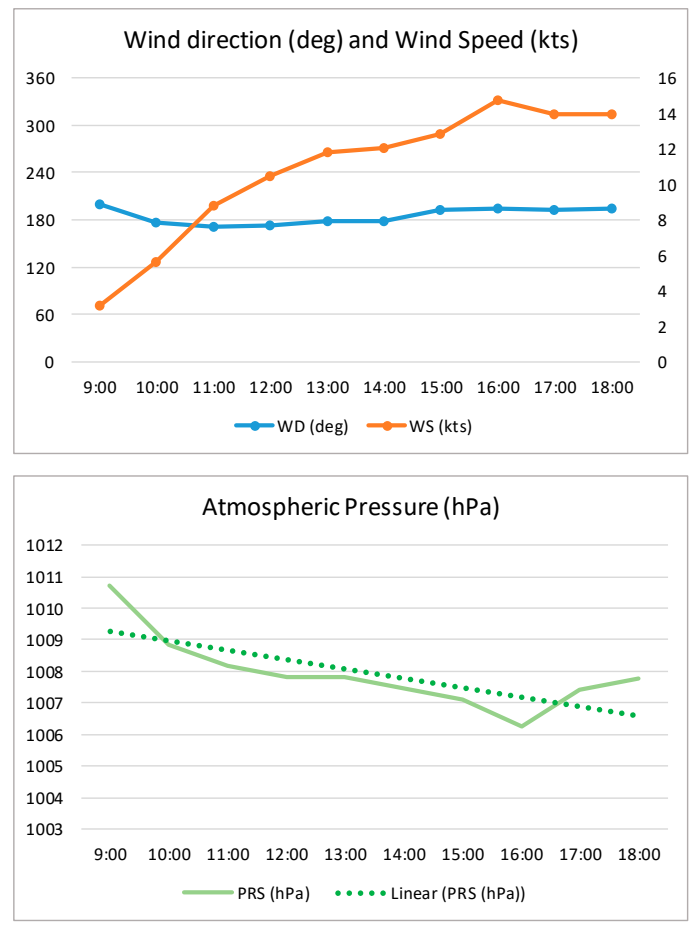

\begin{tabular}{|c|c|c|c|c|}
\hline Date LST & WD (deg) & WS (kts) & PRS (hPa) \\
\hline $27 / 07 / 2016$ 09:00 & 200,1 & 3,1 & 1010,7 \\
\hline $27 / 07 / 2016$ 09:20 & 188,7 & 3,9 & 1010,2 \\
\hline $27 / 07 / 2016$ 09:40 & 181,1 & 4,7 & 1009,4 \\
\hline $27 / 07 / 201610: 00$ & 175,9 & 5,6 & 1008,9 \\
\hline $27 / 07 / 201610: 20$ & 173,8 & 6,7 & 1008,3 \\
\hline $27 / 07 / 201610: 40$ & 172,2 & 7,7 & 1008,7 \\
\hline $27 / 07 / 201611: 00$ & 171,1 & 8,8 & 1008,2 \\
\hline $27 / 07 / 201611: 20$ & 172,1 & 9,3 & 1007,7 \\
\hline $27 / 07 / 201611: 40$ & 173 & 9,9 & 1008,3 \\
\hline $27 / 07 / 201612: 00$ & 173,8 & 10,4 & 1007,8 \\
\hline $27 / 07 / 201612: 20$ & 175,4 & 10,9 & 1007,7 \\
\hline $27 / 07 / 201612: 40$ & 177 & 11,3 & 1008,0 \\
\hline $27 / 07 / 201613: 00$ & 178,4 & 11,8 & 1007,8 \\
\hline $27 / 07 / 201613: 20$ & 178,6 & 11,9 & 1007,3 \\
\hline $27 / 07 / 201613: 40$ & 178,8 & 11,9 & 1007,6 \\
\hline $27 / 07 / 201614: 00$ & 179,1 & 12,0 & 1007,5 \\
\hline $27 / 07 / 201614: 20$ & 183,6 & 12,2 & 1006,9 \\
\hline $27 / 07 / 201614: 40$ & 187,9 & 12,5 & 1007,6 \\
\hline $27 / 07 / 201615: 00$ & 192 & 12,8 & 1007,1 \\
\hline $27 / 07 / 201615: 20$ & 193,1 & 13,5 & 1007,1 \\
\hline $27 / 07 / 201615: 40$ & 194 & 14,1 & 1007,1 \\
\hline $27 / 07 / 201616: 00$ & 194,8 & 14,7 & 1006,2 \\
\hline $27 / 07 / 201616: 20$ & 194,2 & 14,4 & 1006,6 \\
\hline $27 / 07 / 201616: 40$ & 193,5 & 14,2 & 1007,4 \\
\hline $27 / 07 / 201617: 00$ & 192,7 & 13,9 & 1007,4 \\
\hline $27 / 07 / 201617: 20$ & 193 & 13,9 & 1007,8 \\
\hline $27 / 07 / 201617: 40$ & 193,2 & 13,9 & 1007,8 \\
\hline $27 / 07 / 201618: 00$ & 193,5 & 13,9 & 1007,8 \\
\hline $27 / 07 / 201618: 20$ & 194,6 & 13,6 & 1007,8 \\
\hline $27 / 07 / 201618: 40$ & 195,8 & 13,4 & 1007,8 \\
\hline & & & \\
\hline
\end{tabular}

\section{WP2: Hayama [27/07/2016, 09:00LT - 18:00LT]}
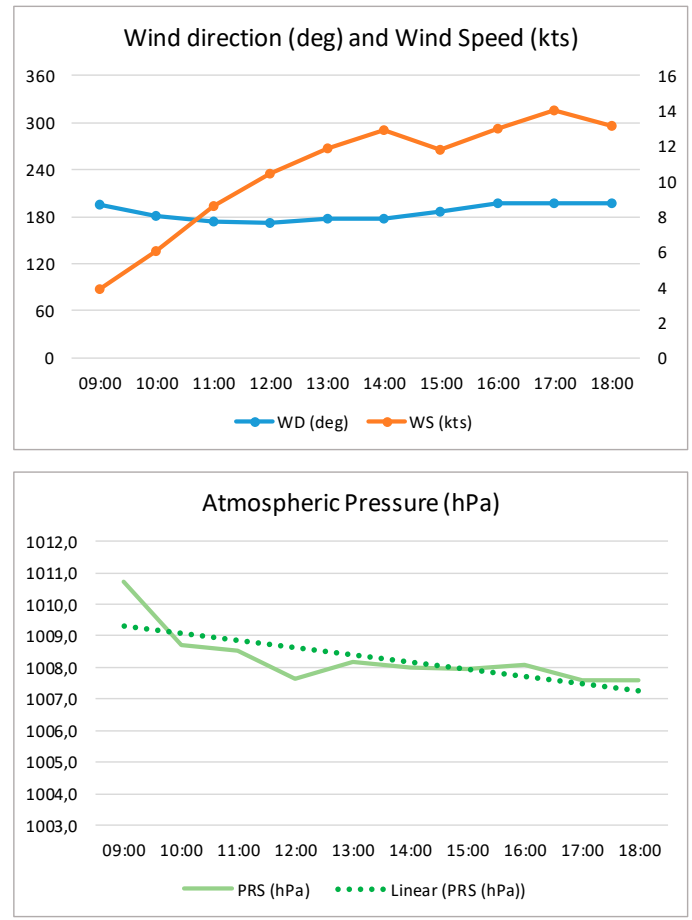

Date LST WD (deg) WS (kts) PRS (hPa)

\begin{tabular}{|l|l|l|l|}
\hline 27/07/2016 09:00 & 195,2 & 3,9 & 1010,7 \\
\hline
\end{tabular}

\begin{tabular}{|l|l|l|l|}
\hline $27 / 07 / 201609: 20$ & 189,1 & 4,6 & 1010,2 \\
\hline
\end{tabular}

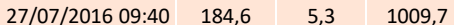

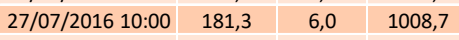

\begin{tabular}{|l|l|l|l|}
\hline $27 / 07 / 201610: 20$ & 177,8 & 6,9 & 1008,7 \\
\hline
\end{tabular}

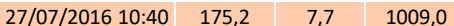

\begin{tabular}{|l|l|l|l|}
\hline $27 / 07 / 201611: 00$ & 173,1 & 8,6 & 1008,5 \\
\hline
\end{tabular}

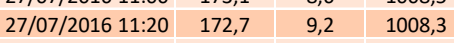

\begin{tabular}{|l|l|l|l|}
\hline $27 / 07 / 201611: 40$ & 172,4 & 9,8 & 1007,8 \\
\hline
\end{tabular}

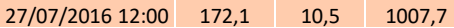

\begin{tabular}{|l|l|l|l|}
\hline 27/07/2016 12:20 & 174,2 & 10,9 & 1008,0 \\
\hline
\end{tabular}

\begin{tabular}{|l|l|l|l|}
\hline $27 / 07 / 201612: 40$ & 176,2 & 11,4 & 1007,8 \\
\hline
\end{tabular}

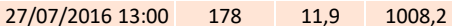

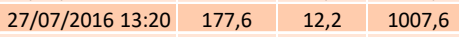

\begin{tabular}{|l|l|l|l|}
\hline $27 / 07 / 201613: 40$ & 177,3 & 12,5 & 1007,6 \\
\hline
\end{tabular}

\begin{tabular}{|l|l|l|l|}
\hline $27 / 07 / 201614: 00$ & 177 & 12,9 & 1008,0 \\
\hline
\end{tabular}

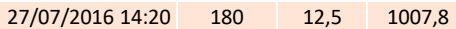

\begin{tabular}{|l|l|l|l|}
\hline $27 / 07 / 201614: 40$ & 183,1 & 12,1 & 1007,3 \\
\hline
\end{tabular}

\begin{tabular}{|l|l|l|l|}
\hline $27 / 07 / 201615: 00$ & 186,4 & 11,8 & 1007,9 \\
\hline
\end{tabular}

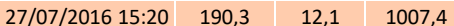

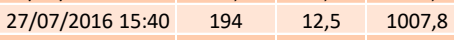

\begin{tabular}{|c|c|c|c|}
\hline $27 / 07 / 201616: 00$ & 197,4 & 13,0 & 1008,1 \\
\hline
\end{tabular}

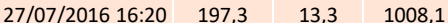

\begin{tabular}{|l|l|l|l|}
\hline $\mathbf{2 7} / 07 / 201616: 40$ & 197,1 & 13,7 & 1007,6 \\
\hline
\end{tabular}

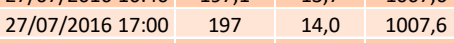

\begin{tabular}{|l|l|l|l|}
\hline $27 / 07 / 201617: 20$ & 197 & 13,7 & 1007,6 \\
\hline
\end{tabular}

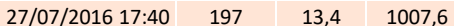

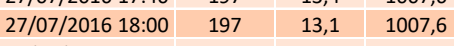

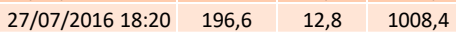

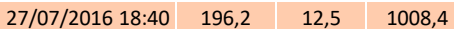

Figure A4. WP2, Enoshima and Hayama race field, 27/07/2016. Wind speed and direction and atmospheric pressure data extracted and simulated on CALMET. 


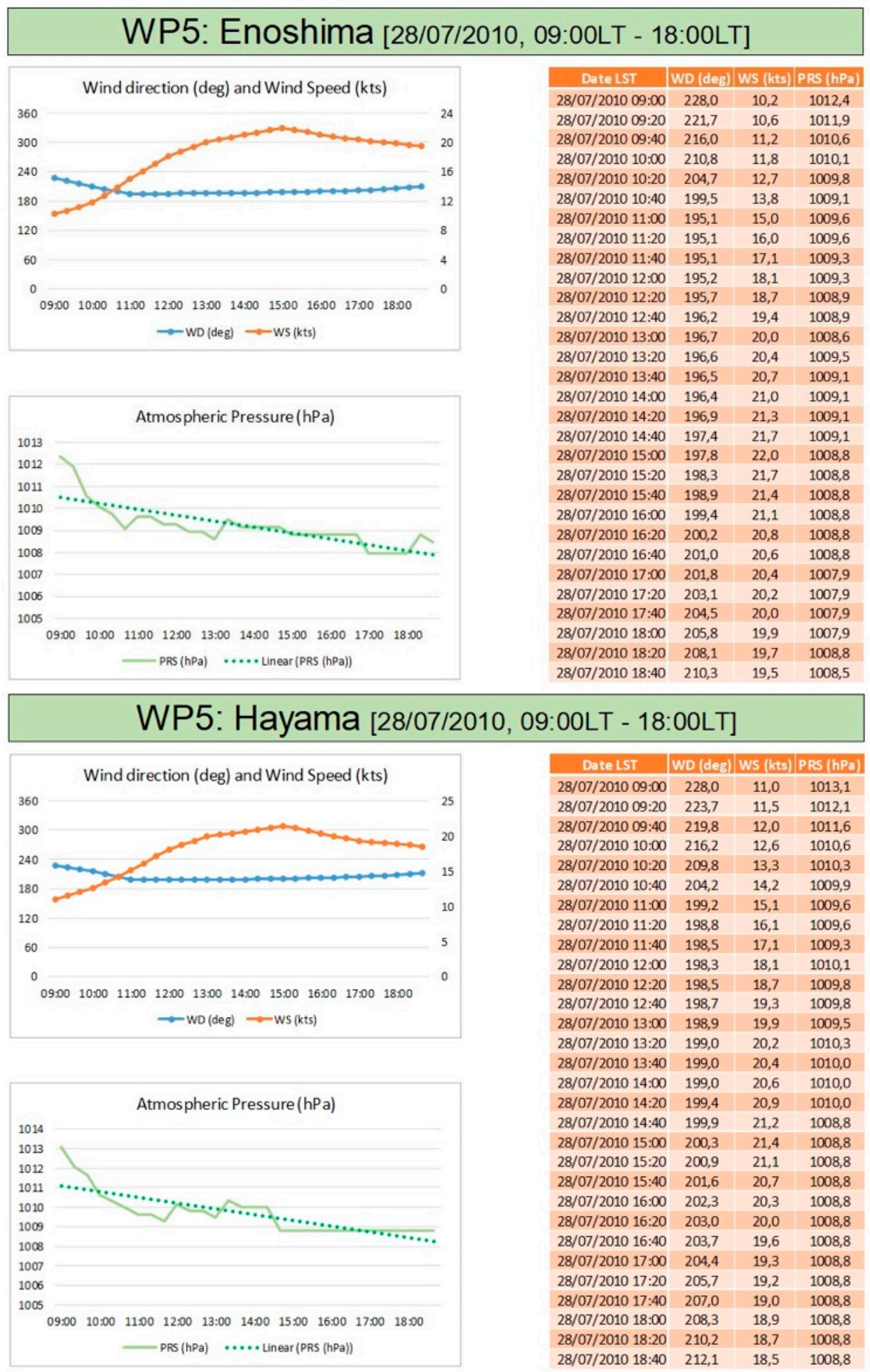

Figure A5. WP5, Enoshima and Hayama race field, 28/07/2010. Wind speed and direction and atmospheric pressure data extracted simulated on CALMET.

\section{References}

1. Hagen, L.J. Evaluation of the Wind Erosion Prediction System (WEPS) erosion submodel on cropland fields. Environ. Model. E Softw. 2004, 19, 171-176.

2. Weber, R.W. Meteorologic variables in aerobiology. Immunol. Allergy Clin. N. Am. 2003, 23, 411-422. [CrossRef]

3. Cogliani, E. Air pollution forecast in cities by an air pollution index highly correlated with meteorological variables. Atmos. Environ. 2001, 35, 2871-2877. [CrossRef] 
4. Traveria, M.; Escribano, A.; Palomo, P. Statistical wind forecast for Reus airport. Meteorol. Appl. 2010, 17, 485-495. [CrossRef]

5. Bellasio, R. Analysis of wind data for airport runway design. J. Airl. Airpt. Manag. 2014, 4, 97-116. [CrossRef]

6. Olayinka, A.S.; Ukhurebor, K.E.; Ogunmola, K.; Aruewamedo, K. Effects of Meteorological Variables on the Efficiency of Solar Panel. J. Niger. Assoc. Math. Phys. 2018, 4.

7. Xu, W.; Ning, L.; Luo, Y. Wind Speed Forecast Based on Post-Processing of Numerical Weather Predictions Using a Gradient Boosting Decision Tree Algorithm. Atmosphere 2020, 11, 738. [CrossRef]

8. El Helou, N.; Tafflet, M.; Berthelot, G.; Tolaini, J.; Marc, A.; Guillaume, M.; Hausswirth, C.; Toussaint, J.F. Impact of environmental parameters on marathon running performance. PLoS ONE 2012, 7, e37407. [CrossRef]

9. Pezzoli, A.; Cristofori, E.; Gozzini, B.; Marchisio, M.; Padoan, J. Analysis of the thermal comfort in cycling athletes. Procedia Eng. 2012, 34, 433-438. [CrossRef]

10. Peiffer, J.J.; Abbiss, C.R. Influence of environmental temperature on $40 \mathrm{~km}$ cycling time-trial performance. Int. J. Sports Physiol. Perform. 2011, 6, 208-220. [CrossRef]

11. Buchheit, M.; Voss, S.C.; Nybo, L.; Mohr, M.; Racinais, S. Physiological and performance adaptations to an in-season soccer camp in the heat: Associations with heart rate and heart rate variability. Scand. J. Med. Sci. Sports 2011, 21, 477-485. [CrossRef] [PubMed]

12. Pezzoli, A.; Bellasio, R. Computer supported analysis of thermal comfort for cycling sport. Sport Sci. Res. Technol. Support 2016, 71-85.

13. Golding, B.W.; Ballard, S.P.; Mylne, K.; Roberts, N.; Saulter, A.; Wilson, C.; Agnew, P.; Davis, L.S.; Trice, J.; Jones, C.; et al. Forecasting capabilities for the London 2012 Olympics. Bull. Am. Meteorol. Soc. 2014, 95, 883-896. [CrossRef]

14. Li, X. Coastal wind analysis based on active radar in Qingdao for Olympic sailing event. In The International Archives of the Photogrammetry, Remote Sensing and Spatial Information Sciences; ISPRS: Bejing, China, 2008; Volume 37, pp. 653-658.

15. Giannaros, T.M.; Kotroni, V.; Lagouvardos, K.; Dellis, D.; Tsanakas, P.; Mavrellis, G.; Symeonidis, P.; Vakkas, T. Ultrahigh resolution wind forecasting for the sailing events at the Rio de Janeiro 2016 Summer Olympic Games. Meteorol. Appl. 2018, 25, 86-93. [CrossRef]

16. Spark, E.; Connor, G.J. Wind forecasting for the sailing events at the Sydney 2000 Olympic and Paralympic Games. Weather Forecast. 2004, 19, 181-199. [CrossRef]

17. Messager, C.; Badham, R.C.; Honnorat, M.; Vandenberghe, F.; Waterhouse, T.; Currie, I. Weather forecast for the 35th America's Cup (2017) winners based on a limited area model. Meteorol. Appl. 2020, 27, e1879. [CrossRef]

18. Tagliaferri, F.; Viola, I.M. A real-time strategy-decision program for sailing yacht races. Ocean Eng. 2017, 134, 129-139. [CrossRef]

19. Pezzoli, A.; Bellasio, R. Analysis of Wind Data for Sports Performance Design: A Case Study for Sailing Sports. Sports 2014, 2, 99-130. [CrossRef]

20. Kikuchi, Y.; Arakawa, S.; Kimur, F.; Shirasaki, K.; Nagano, Y. Numerical study on the effects of mountains on the land and sea breeze circulation in the Kanto district. J. Meteorol. Soc. Jpn. 1981, 59, 723-738. [CrossRef]

21. Hinata, H.; Yanagi, T.; Takao, T.; Kawamura, H. Wind-induced Kuroshio warm water intrusion into Sagami Bay. J. Geophys. Res. 2005, 110. [CrossRef]

22. Weather Research and Forecasting Model. Available online: https://www.mmm.ucar.edu/weather-research-and-forecastingmodel (accessed on 22 October 2020).

23. Scire, J.S.; Robe, F.R.; Fernau, M.E.; Yamartino, R.J. A User's Guide for the CALMET Meteorological Model (Version 5.0); Earth Tech Inc.: Concord, MA, USA, 1999.

24. Bellasio, R.; Maffeis, G.; Scire, J.S.; Longoni, M.G.; Bianconi, R.; Quaranta, N. Algorithms to Account for Topographic Shading Effects and Surface Temperature Dependence on Terrain Elevation in Diagnostic Meteorological Models. Bound. Layer Meteorol. 2005, 114, 595-614. [CrossRef]

25. Schlager, C.; Kirchengast, G.; Fuchsberger, J. Empirical high-resolution wind field and gust model in mountainous and hilly terrain based on the dense WegenerNet station networks. Atmos. Meas. Tech. 2018, 11, 5607-5627. [CrossRef]

26. Schlager, C.; Kirchengast, G.; Fuchsberger, J. Generation of high-resolution wind fields from the dense meteorological station network WegenerNet in south-eastern Austria. Weather Forecast. 2017, 32, 1301-1319. [CrossRef]

27. WindRose PRO3. Available online: https://www.enviroware.com/portfolio/windrose-pro3/ (accessed on 22 October 2020).

28. Moriarity, R.J.; Liberda, E.N.; Tsuji, L.J. Using a geographic information system to assess local scale methylmercury exposure from fish in nine communities of the Eeyou Istchee territory (James Bay, Quebec, Canada). Environ. Res. 2020, 191, 110147. [CrossRef]

29. Lu, B.; Stocks, M.; Blakers, A.; Anderson, K. Geographic information system algorithms to locate prospective sites for pumped hydro energy storage. Appl. Energy 2018, 222, 300-312. [CrossRef]

30. Dijkink, S.; Winchell, R.J.; Krijnen, P.; Schipper, I.B. Quantification of Trauma Center Access Using Geographical Information System-Based Technology. Value Health 2020, 23, 1020-1026. [CrossRef]

31. Zambrano, L.I.; Rodriguez, E.; Espinoza-Salvado, I.A.; Fuentes-Barahona, I.C.; de Oliveira, T.L.; da Veiga, G.L.; da Silva, J.C.; Valle-Reconco, J.A.; Rodríguez-Morales, A.J. Spatial distribution of dengue in Honduras during 2016-2019 using a geographic information systems (GIS)-Dengue epidemic implications for public health and travel medicine. Travel Med. Infect. Dis. 2019, 32, 101517. [CrossRef] 
32. Ogato, G.S.; Bantider, A.; Abebe, K.; Geneletti, D. Geographic information system (GIS)-Based multicriteria analysis of flooding hazard and risk in Ambo Town and its watershed, West shoa zone, oromia regional State, Ethiopia. J. Hydrol. Reg. Stud. 2020, 27, 100659. [CrossRef]

33. Hossain, M.S.; Gadagamma, C.K.; Bhattacharya, Y.; Numada, M.; Morimura, N.; Meguro, K. Integration of smart watch and Geographic Information System (GIS) to identify post-earthquake critical rescue area part. I. Development of the system. Prog. Disaster Sci. 2020, 7, 100116. [CrossRef]

34. Amazon Web Services. Available online: https://aws.amazon.com/it/what-is-aws/ (accessed on 22 October 2020).

35. SRTM Data. Available online: https://www2.jpl.nasa.gov/srtm/ (accessed on 22 October 2020).

36. JAXA Land Use Data. Available online: https://www.eorc.jaxa.jp/ALOS/en/lulc/lulc_index.htm (accessed on 22 October 2020).

37. Dudhia, J. Numerical study of convection observed during the Winter Monsoon Experiment using a mesoscale two-dimensional model. J. Atmos. Sci. 1989, 46, 3077-3107. [CrossRef]

38. Kain, J.S.; Kain, J. The Kain-Fritsch convective parameterization: An update. J. Appl. Meteorol. 2004, 43, 170-181. [CrossRef]

39. Hong, S.-Y.; Noh, Y.; Dudhia, J. A new vertical diffusion package with an explicit treatment of entrainment processes. Mon. Weather. Rev. 2006, 134, 2318-2341. [CrossRef]

40. Mlawer, E.J.; Taubman, S.J.; Brown, P.D.; Iacono, M.J.; Clough, S.A. Radiative transfer for inhomogeneous atmospheres: RRTM, a validated correlated-k model for the longwave. J. Geophys. Res. Atmos. 1997, 102, 16663-16682. [CrossRef]

41. Lin, Y.; Farley, R.; Orville, H. Bulk Parameterization of the Snow Field in a Cloud Model. J. Clim. Appl. Meteorol. 1983, 22, 1065-1092. [CrossRef]

42. Powell, M.D.; Rinard, S.K. Marine forecasting at the 1996 centennial Olympic games. Weather Forecast. 1998, 13, 764-782. [CrossRef]

43. Ma, Y.; Gao, R.; Xue, Y.; Yang, Y.; Wang, X.; Liu, B.; Xu, X.; Liu, X.; Hou, J.; Lin, H. Weather support for the 2008 Olympic and Paralympic sailing events. Adv. Meteorol. 2013, 2013, 289284. [CrossRef]

44. Bai, Y.; Li, Y.; Wang, X.; Xie, J.; Li, C. Air pollutants concentrations forecasting using back propagation neural network based on wavelet decomposition with meteorological conditions. Atmos. Pollut. Res. 2016, 7, 557-566. [CrossRef]

45. Hernández, A.; Saavedra, S.; Rodríguez, A.; Souto, J.A.; Casares, J.J. Coupling WRF and CALMET models: Validation during primary pollutants glc episodes in an Atlantic coastal region. In Air Pollution Modeling and Its Application, 22nd ed.; Springer: Dordrecht, The Netherlands, 2014; pp. 681-684.

46. Sun, W.; Sun, J. Daily PM2. 5 concentration prediction based on principal component analysis and LSSVM optimized by cuckoo search algorithm. J. Environ. Manag. 2017, 188, 144-152. [CrossRef] [PubMed]

47. González, J.A.; Hernández-Garcés, A.; Rodríguez, A.; Saavedra, S.; Casares, J.J. Surface and upper-air WRF-CALMET simulations assessment over a coastal and complex terrain area. Int. J. Environ. Pollut. 2015, 5, 249-260. [CrossRef]

48. Houghton, D.; Campbell, F. Wind Strategy, 3rd ed.; John Wiley \& Sons Inc.: London, UK, 2006. 